\title{
بناء معايير للتقويم والاعتماد المدرسلي للمدارس الحكومية بسلطنة عُمان
}

بدرية بنت حمود بن ناصر المحروقية، علي عبد جاسه الزاملي؛ محمود محمد إبراهيه3

1وزارة التربية والتعليم-سلطنة عُمان

2 أستاذ مشارك (سابق) بقسم علم النفس- كلية التربية-جامعة السلطان قابوس- سلطنة عُمان 3 أستاذ مشارك القياس والتقويم- كلية التربية- جامعة السلطان قابوس- سلطنة عُمان

${ }^{1}$ Someone4941@gmail.com, ${ }^{2}$ aljassimali3@gmail.com, ${ }^{3}$ Mibrahim@squ.edu.om

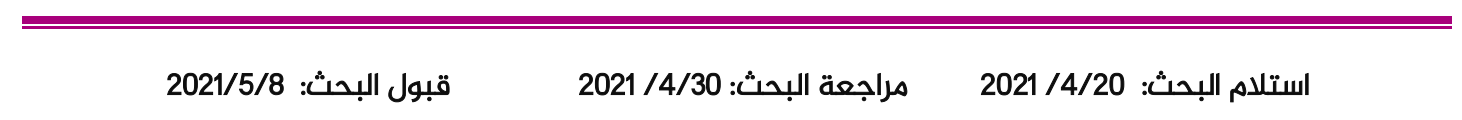


بناء معايير للتقويم والاعتماد المدرسي للمدارس الحكومية بسلطنة عُمان

\author{
بدرية بنت حمود بن ناصر المحروقية'، علي عبد جاسم الزاملي، محمود محمد إبراهيم3 \\ 1 وزارة التربية والتعليم-سلطنة عُمان
}

2²

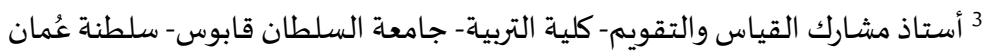

1. Someone4941@gmail.com, ${ }^{2}$ aljassimali3@gmail.com, ${ }^{3}$ Mibrahim@squ.edu.om

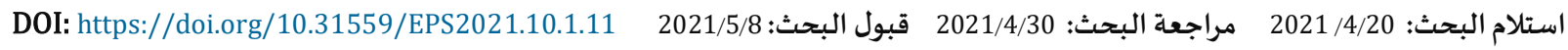

\begin{abstract}
هدفت الدراسة الحالية إلى بناء معايير للتقويم والاعتماد المدرسي للمدارس الحكومية بسلطنة عُمان؛ حيث اتبعت الدراسة المنهج الوصفي، المارئ

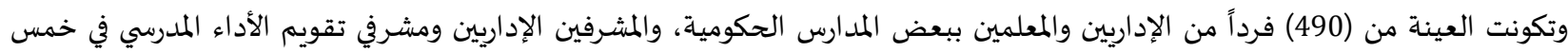

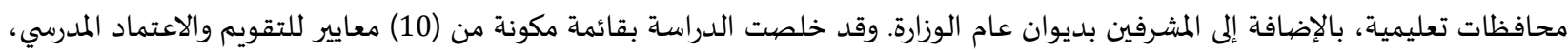

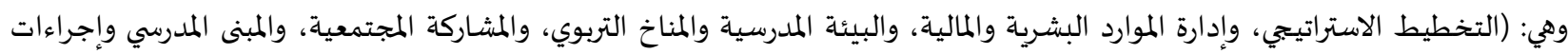

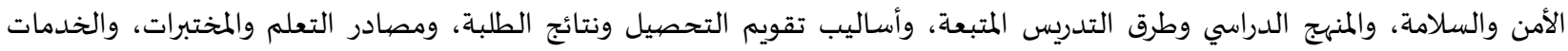

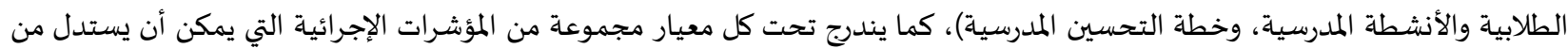

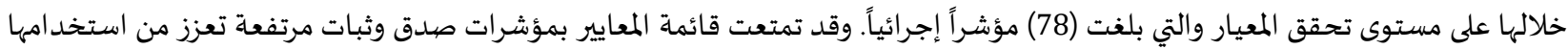
لأغراض التقويم والاعتماد المدرسي.
\end{abstract} الكلمات المفتاحية: الاعتماد المدرسي؛ المعايي؛؛ المدارس الحكومية؛ سلطنة عُمان.

تفرض التحولات العالمية الحديثة في الاتجاهات الاجتماعية والاقتصادية والمعرفية على الأنظمة التربوية بأن تتجها إلى استحداث نظم تقويمية ذات

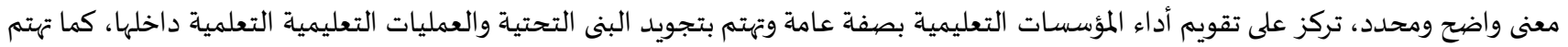

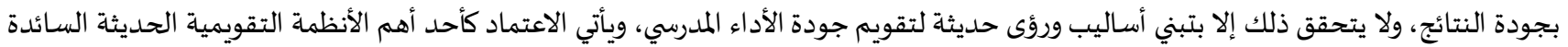

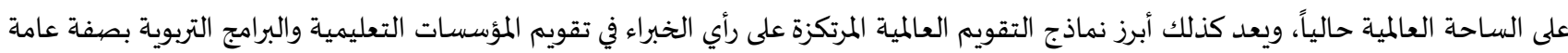

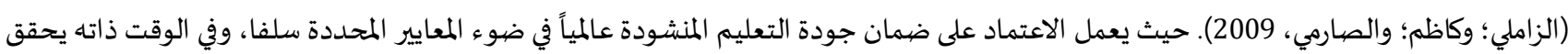

فاعلية تحقيق أهداف التقويم، وكفاءة المخرجات والنتائج بأقل كلفة (الجهني، 2010 2010).

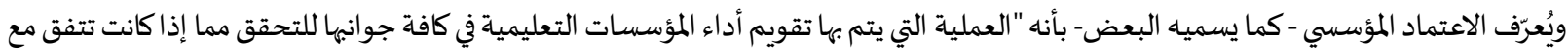

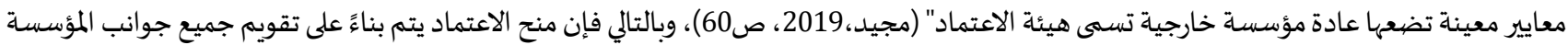

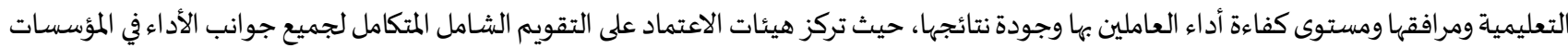

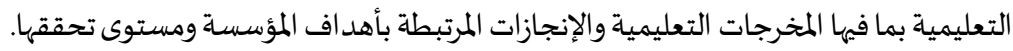
وبحسب مجيد (2011) فإن حركة الاعتماد قد ارتبطت بظهور حركتين رئيسيتين هما ضمان المرانيان الجودة والمعايير التربوية، حيث تعتبر المعايير من 
الأسس العلمية الهامة لتقويم جودة البرامج والمؤسسات التربوية والتعليمية وتعمل على تحسين أدائها وضمان جودتها، كما أهها تعمل على تحديد مستوى الإنجاز المتوقع من خلال وضع مجموعة من المؤشرات التي تصف مستوى الأداء بطريقة إجرائية قابلة للقياس، ووفقاً للزاملي وآخرون (2009)

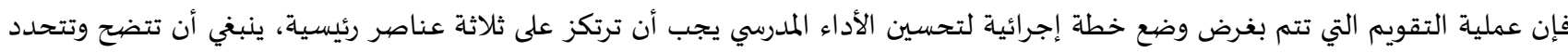

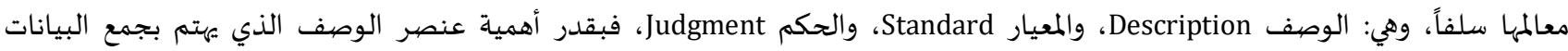

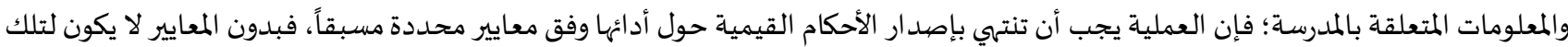

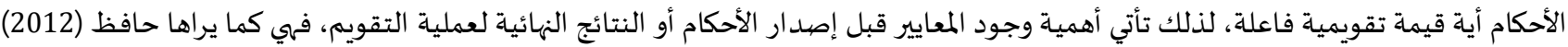
تعتبر بمثابة المحك الذي يميز بين الواقع والمطلوب في العملية التعليمياة. وترجع أهمية المعايير التربوية إلى أهها أصبعت واحتدة من أكثر الأدوات المستخدمة للحكم على مستوى إنجاز المؤسسات التعليمية لمهامها وأهدافها،

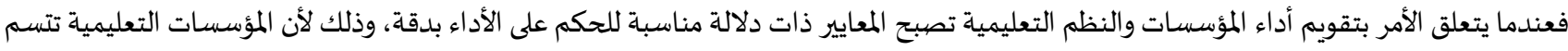
بخصائص من أبرزها صعوبة قياس أدائها بشكل مباشر ودقيق (مجاهد، 2008)، وفي هذا الشأن ذكر آل رفعة (2015) أن تطبيق معايير الاعتماد والجوة في

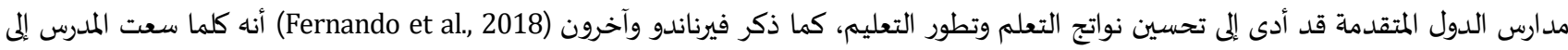

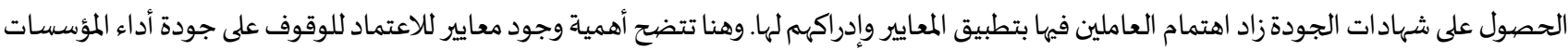

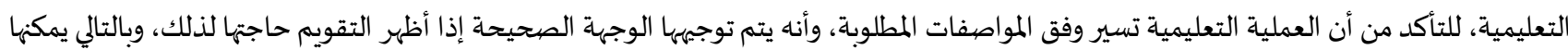
أن تحقق أقصى مستويات الكفاءة والجودة المنشودة.

ففي الولايات المتحدة الأمريكية تم تبني نظم الاعتماد منذ أكثر من مائة عام، فقد نشأ الاعتماد ليميز بين المؤسسات التعليمية من حيث القدرة

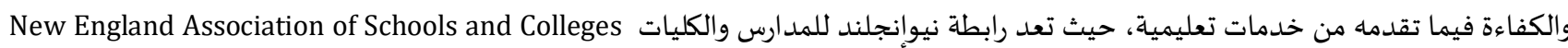
(NEASC) الجمعية باعتماد أكثر من 2000 مؤسسة تعليمية من القطاعين العام والخاص (Fryer, 2007). وفي إنجلترا يتولى مكتب المعايير التربوية من موسية Office for Standards In Education (OFSTED) الذي تأسس عام 1992م مسؤولية الاعتماد

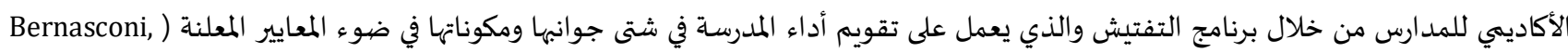

أما على مستوى الوطن العربي فتعتبر تجربة جمهورية مصر العربية من أوائل التجارب في مجال الاعتماد المدرسي، ففي عام 2006م تم إقرار إنشاء

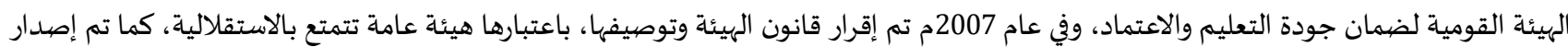

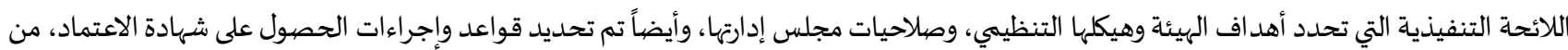

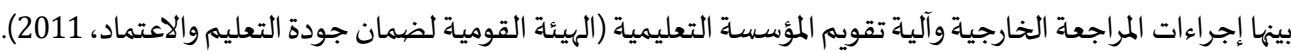

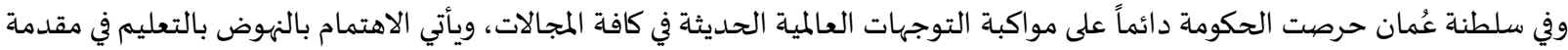
تلك المجالات والاهتمامات، حيث بذلت السلطنة جهوداً متعددة في تطوير التعليم، ومن بين تلك الجهود إنشاء مجلس الاعتماد الأكاديمي، والذي بألئي

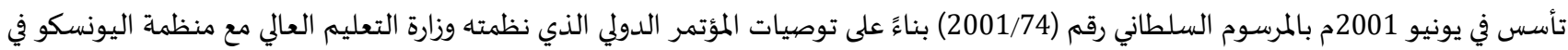
مارس 2001م حول جامعة القرن الواحد والعشرين. وفي عام 2010م صدر المرسوم السلطاني رقم (45/ 2010) والذي يقضي بتحويل مجلس الاعتماد

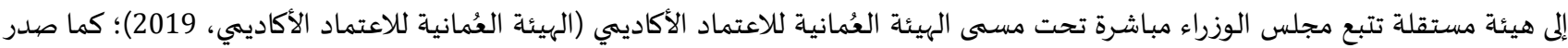

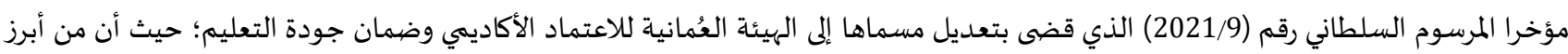
الاختصاصات التي تم إضافتها تقويم المدارس الحكومية والخاصية وفقاً للمعايير والإجراءات التي تضعها الهيئة (وزارة الشؤون القانونية، 2021).

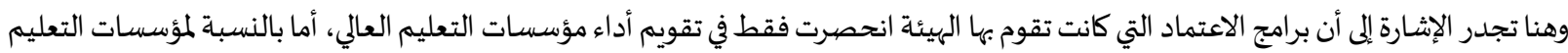

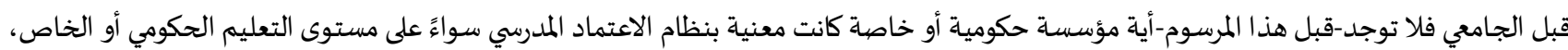

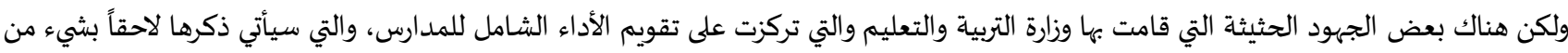
التفصيل في مشكلة الدراسة. إن جهود السلطنة في الاعتماد المدرسي أو الأكاديمي تتضح جلياً في اقتصارها على مؤسسات التعليم العالي دون المدارس، مما يبرر القيام بهذه الدراسة

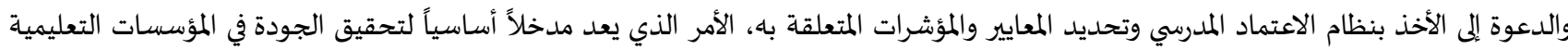

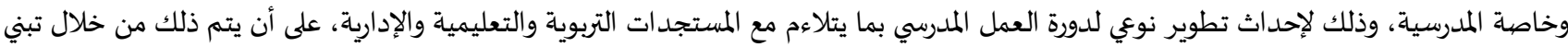
معايير واضحة ومقننة لتقويم فعالية وكفاءة تلك المؤسسات ودفعها للقيام بدراسات ذاتية وتقويمية Self-study، الأمر الذي يؤدي إلى تعزيز ثقة المجتمع في فئه نظام التعليم وومؤسساته كافة. 
1.1. مشكلة الدراسة وأسئلتها:

تؤكد العديد من الدراسات الأجنبية والعببية (Fryer, 2007, Burris, 2008 ؛ Plwahaibi, 2009 Provezis, 2010 والمالكي، 2010؛ والسيابي، 2012، وآل رفعاة، 2015، والربادي، 2020) بأن الاعتماد يعدّ نموذجاً تقويمياً مناسباً للتأكد من تحقيق المدرسة لأهدافها، ويمكنها من المان

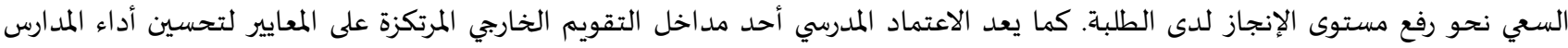

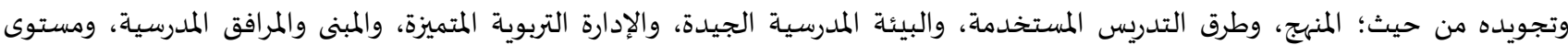

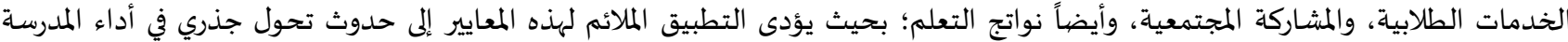
ليواكب ركب العالمية والانفجار المعرفي والتكنولوجي المتسارع، وقد اعتبر ساونديرس(Saunders, 2010) الاعتماد حجر الأسـاس الذي ينطلق منسئه التقويم الذاتي للمدرسة، فهو يحقق أهدافه المزدوجة من خلال عمليتي التقويم الذاتي والتقويم الخارجي المبني على المعايير المحددة والمقننة والتي يتم

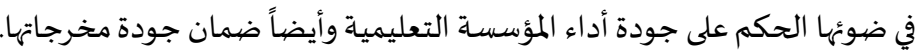

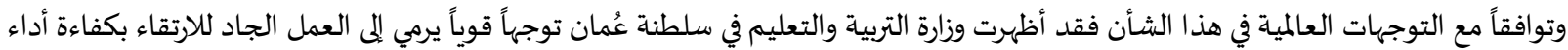
المدارس الحكومية والخاصة على حد سواء، يتضح ذلك من خلال سعي الوزارة إلى تبني نظام تقويمي شامل يتمثل في مشروع تقويم الأداء المدرسي وتطويره،

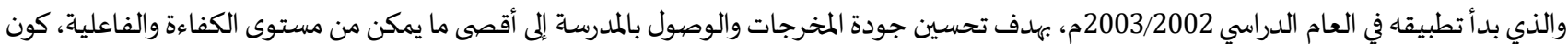
التقويم عملية تشخيصية تهدف إلى تحديد نقاط القوة وأولويات التطوير في العملية التعليمية من خلال تطبيق نظام التقويم الذاتي لأداء المدرسة، كما هدف

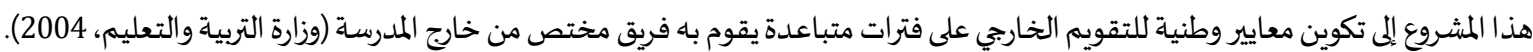
وفي عام 2006م استحدثت الوزارة نظام تطوير الأداء المدرسي كأهم توصية أفرزها نتائج مشروع تقويم الأداء المدرسي، وذلك في القرار الوزاري رقم (2006/19)، حيث تم إعداد صيغة تقويمية متكاملة لتقويم الأداء المدرسي شملت ثلاثة مجالات هي: التعليم والتعلم والإدارة المدرسياة، مضمنئة

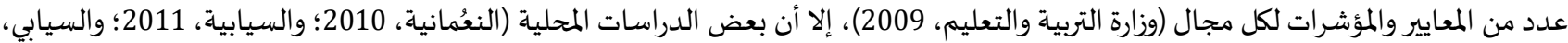
2012) أشارت إلى قصور وتداخل بعض المعايير خاصة ما يتعلق بمجالي التعليم والتعلم، وغياب المعايير المرتبطة بالقيم السلوكية والمستويات التحصيلية، بالإضافة إلى عدم توافق بعضها الآخر مع مهام العاملين بالمدرسة، وضيعف عملية التقويم الخارجي، إضافة لافتقار المعايير لعنصري

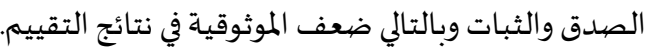
كما أشـارت دراسات كل من اليعربي (2012) والمنوري (2014) إلى عدم وضوح معايير التقويم ومؤشراته مما يتسبب في ضيعف فئست فاعلية تقويم الأداء وقصور انعكاساته على عمليات التطوير والتحسين بالمدارس العُمانية، كما اتفقت في ذلك دراسات كل من إبراهيم والمرزوقي (2017) والراسبية (2020) من حيث غموض أهداف ومعايير النظام الحالي وضعف شموليتها وعدم تغطيتها لكافة جوانب العمل المدرسي، وضعف إدهاء إجراءات التقويم وقصيور أدواته، وبالتالي محدودية البيانات والمعلومات الناتجة عن عمليات التقويم المختلفة.

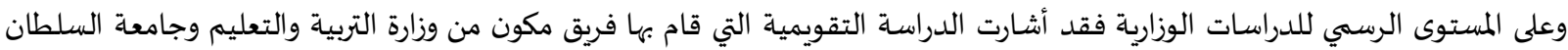
قابوس، والتي أجريت لتقويم نظام تطوير الأداء المدرسي إلى أهمية إضافة عناصر أكبر وأشمل للنظام مثل مشاركة المجتمع المحلي في تحسين وتطوير أداء

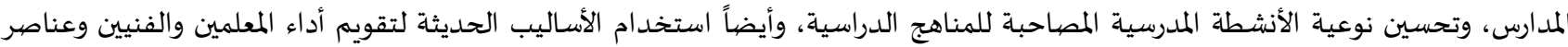
الإدارة المدرسية،، بالإضافة إلى ضرورة وضع معايير واضحة لتقويم تحصيل الطلبة مشمولة باختبارات عالمية مقننة للارتقاء بمستوياتهم الدراسية، كما

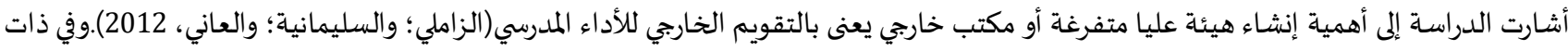

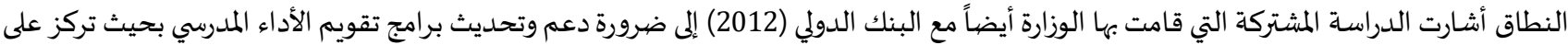

جودة الأداء والمخرجات معاً وفق معايير عالمية.

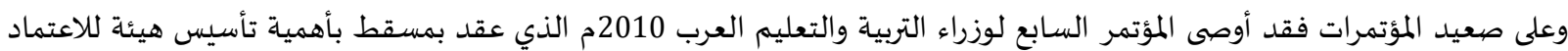
وضمان الجودة في التعليم الثانوي، تتبنى اعتماد معايير لتطوير الأداء المؤسسي للمؤسسات التعليمية، على أن تكون هذه المعايير ذات قابلية للتطبيق

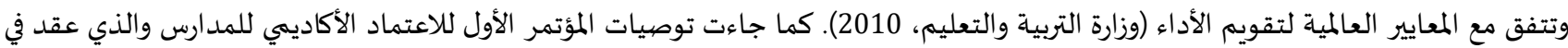
مسقط أيضاً في إبريل 2012م، مؤكدة على أهمية توفير معايير محلية خاصة بالسلطنة للتقويم والاعتماد المدرسي، مع ضرورة الاستفادة من الخبرات

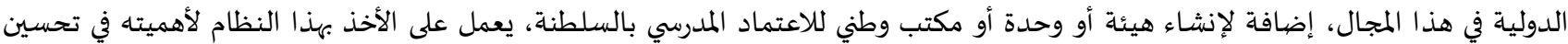
وتطوير أداء المدارس بشكل عام (وزارة التربية والتعليم، 2012). واستجابة لتلك التوصيات واستكمالاً لمسيرة التطوير التي تحرص عليها وزارة التربية والتعليم جاء إنشاء المركز العُماني لتقييم المدارس في عام 2015 بمباركة من مجلس التعليم بالسلطنة، والذي يهدف إلى مراجعة الإطار العام لنظام تطوير الأداء المدرسي والعمل على تطوير معايير لتقويم الأداء المدرسي في ضوء الخبرات الدولية تحقيقا لجودة الأداء المنشود (مجلس التعليم، 2017)، ثم تم تعديل مسمى المركز إلى المديرية العامة لتقييم المدارس في ضوء السلطاني رقم (2020/79) الذي صدر لإعادة هيكلة وزارة التربية والتعليم في السلطنة وتحديد اختصاصاتها (وزارة الشؤون القانونية، 2020)، تلا ذلك المرسوم 
السلطاني رقم (2021/9) الذي قضى بنقل تبعية هذه المديرية واختصاصاتها وموظفيها إلى الهيئة العُمانية للاعتماد الأكاديمي وضمان جودة التعليم (وزارة الشؤون القانونية، 2021) بهدف تجويد مخرجات النظام التعليمي والارتقاء بالأداء المدرسي في ضوء عمليات تقويم شاملة تتصف بالشفافية والمصيداقية العالية تقوم بها جهة مستقلة ومحايدة عن الوزارة. وفي هذا الصدد أُجريت عدة مقابلات مع عدد من المسؤولين والمختصين بوزارة التربية والتعليم خلال شهر فبراير 2020م؛ حيث اتضح أنحارة أن

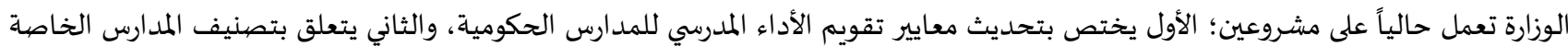
وفق معايير محددة لكل مستوى تصنيفي؛ حيث لم تنتاه فرق العمل بالمشروعين من وضع كافة الأطر الفنية والإدارية اللازمة للتنفيذ الميداني. وفي ضوء ما سبق ونظرًا لأهمية موضيوع الاعتماد المدرسي وما يرمي إليه من أهداف استراتيجية لتقويم الأداء المدرسي وتحسين فئن عملياته وتجويد

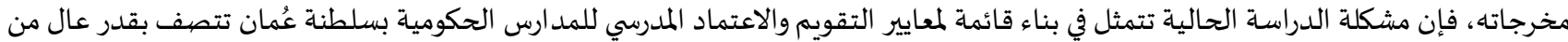
الصدق والثبات مما يسمح باستخدامها في عمليات تقويم الأداء المستقبلية، وبالتالي فإن مشكلة الدراسة تثير الأسئلة التهائة التالية:

ما قائمة المعايير المقترحة للتقويم والاعتماد المدرسي للمدارس الحكومية بسلطنة عُمان؟ ما مؤشرات صدق قائمة معايير التقويم والاعتماد المدرسي للمد ارس الحكومية بسلطنة عُمان؟ ما مؤشرات ثبات قائمة معايير التقويم والاعتماد المدرسي للمدارس الحكومية بسلطنة عُمان؟

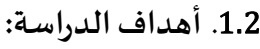
تهدف الدراسة الراهنة إلى: تحديد قائمة بالمعايير والمؤشرات الخاصة بالتقويم والاعتماد المدرسي للمدارس الحكومية بسلطنة عُمان، تتلاءم مع طبيعة النظام التعليمي

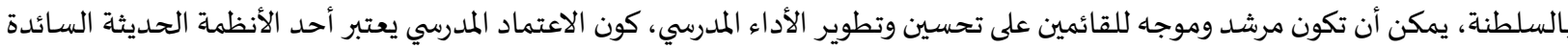

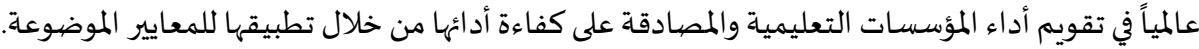
التحقق من صدق قائمة معايير الاعتماد المدرسي المقترحة لتقويم أداء المدارس الحكومية بسلطنة عُمان. التأكد من ثبات قائمة معايير الاعتماد المدرسي المقترحة لتقويم أداء المدارس الحكومية بالسلطنة.

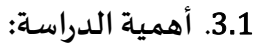
تكمن أهمية هذه الدراسة في أهها: تقدم معايير ومؤشرات عملية موضيوعية للاعتماد المدرسي تعتمد على تطبيق الأسـاليب العلمية لبناء المعايير المستخدمة في القياس والتقويم من حيث تمتعها بالخصائص السيكومترية الجيدة. تسلط الضوء على نظام الاعتماد المدرسي كونه وسيلة فعالة لتحقيق الجودة التعليمية وضمان تطبيقها، بوصفه عملية تقويم مستمرة لجودة

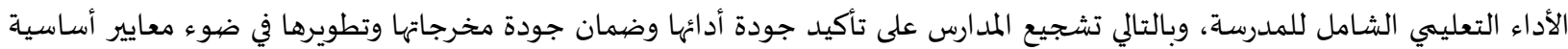
ومؤشرات واضحة متفق عليها. قد تمد هذه الدراسة المسئولين في وزارة التربية والتعليم في سلطنة عُمان بالمعايير والمؤشرات النوعية والكمية الواجب توافرها في المدارس

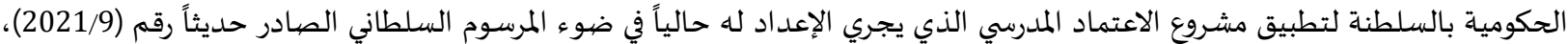
حيث تعد هذه الدراسـة -على حد علم الباحثين- من الدراسات الرائدة في مجال بناء المعايير التربوية في السلطنة والخاصة بالاعتماد المدرسي.

تتضيمن الدراسة الحالية عدة مصطلحات الدرات، يمكن تعريفها كما يلي: الاعتماد المدرسي School Accreditation: عرفت فراير (Fryer, 2007) الاعتماد بأنه " العملية التي يتم بواسطتها تقويم المؤسسة التعليمية للتأكد من استيفائها للمعايير والمتطلبات المحددة من قبل جهة رسمية"(P10). أما درندري والنافع (2009) فقد عرفوا الاعتماد المدرسي على أنه "عملية تقويمية

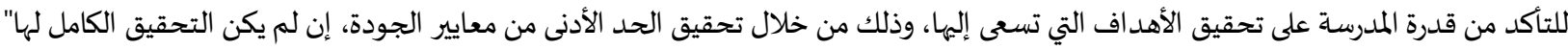

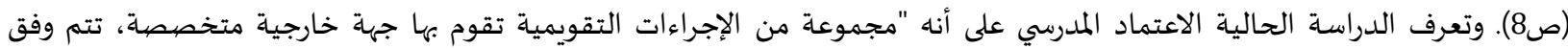

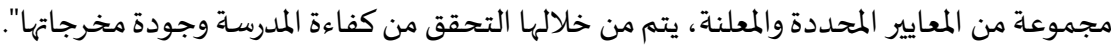
المعايير Standards: عرفها بوريس (Burris, 2008) بأنها "عبارة عن شروط ثابتة توضع للتميز النوعي المطلوب من جميع المدارس والتي تحددها جهة الاعتماد" (P 8)، كما عرفتها النعُمانية (2010) على أهها "القواعد والأسس التي نحتكم إليها وتكون بمثابة الإطار المرجعي الذي يتم في ضيونئه

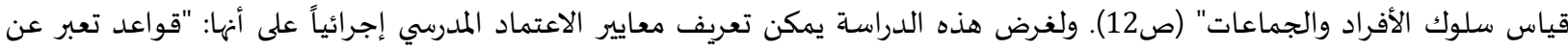


المستوى المطلوب الذي يجب أن تحققه مكونات وعناصر المدرسة للحصول على الاعتماد المدرسي، وتتمثل في الدرجة التي يحصل عليها كل معيار

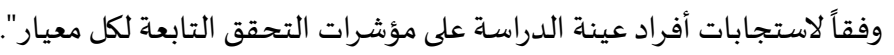

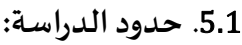

هالحدود الموضوعية: تتناول هذه الدراسـة مفهوم الاعتماد المدرسي باعتباره أحدث الأنظمة التقويمية المتبعة عالمياً لضمان جودة التعليم

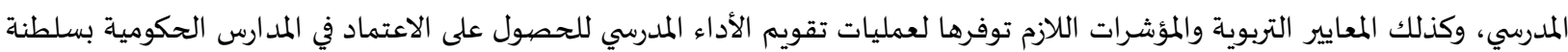

عُمان. الحدود البشرية: شملت الدراسة عينة من المشرفين الإداريين وأخصائي تقويم الأداء المدرسي بالمحافظات وديوان عام الوزارة، نظراً لمسؤوليتهم

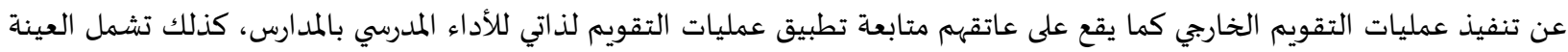

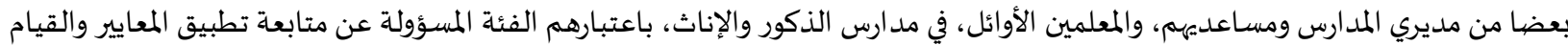
بعمليات التقويم الذاتي بالمدرسة. الحـدود المكانية: اقتصرت الدراسة على خمس محافظات تعليمية (مسقط، والداخلية، وشمال الشرقية، وشمال الباطنة، وظفار)، حيث تم مراعاة أن تغطي الدراسة مختلف البيئات التي تمثل جغرافية السلطنة، كما اقتصر التطبيق على مدارس الحلقة الثانية من التعليم الأساسي الحكومي فقط، لأنس هذه الحلقة تمثل القاعدة العريضة من حيث عدد الصفوف مقارنة بالحلقات الأخرى للتعليم في السلطنة، حيث تضم الصفوف من الخامس الأساسي وحتى العاشر الأساسي، إضافة إلى أن بعض المدارس بالمحافظات المذكورة تضم إما الحلقة الأولى مع الحلقة الثانية أو الحلقة الثانية مع الصفين الحادي مئي

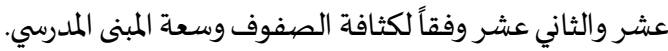

2. الإطار النظري والدراسات السابقة:

تعتبر قضية تحقيق الجودة في التعليم من أهم القضايا التي تشغل بال المهتمين بالعملية التعليمية في كافة المستويات والأصعدة، وما قد

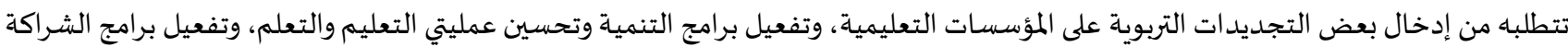
الحقيقية بين المدرسة والمؤسسات المجتمعية الأخرى، وبالتالي الحصيول على مخرجات تعليمية عالية الكفاءة والمهارة.

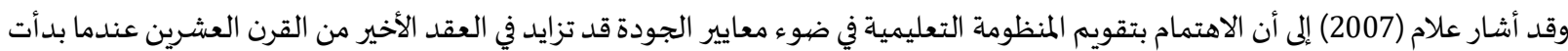
اليونسكو تدعو الدول إلى مشروع المعايير والمؤشرات التربوية، وذلك إيماناً منها بالمسؤولية الكبرى تجاه قضية جودة المهاء التعليم، فقد أكد مؤتمر "التربية

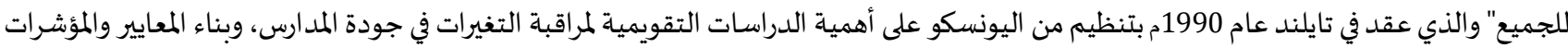
التربوية لضبط أداء المدارس على مدى فترات زمنية معينة. كما أشارت الرميح (2013) إلى أن تقرير اليونسكو الصادر في عام 2008 قد أوصى بضرورة تركيز

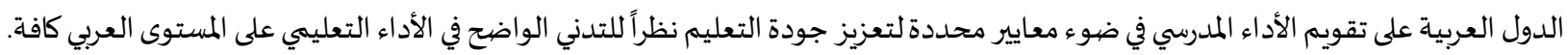
وترجمة لذلك فقد استخدمت الكثير من دول العالم أساليب متعددة لضميمان الجودة وتقويمها، من بين تلك الأساليب الاعتماد التربوي أو المدرسي، وهو يمثل أحد الأساليب المعروفة لإجراء عملية تقويم شاملة لأي مؤسسة تربوية، وهو في جوهره عملية تقويم لأداء المؤسسة التعليمية تضمن جودئ دودة مخرجاتها؛

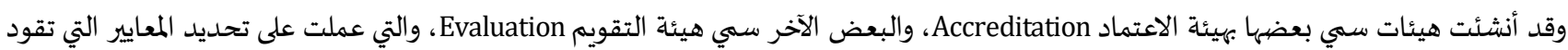
العمل في المؤسسات التعليمية (مجيد،2011). ففي الولايات المتحدة الامريكية يعد الاعتماد التربوي من أهم العوامل التي تستند إلهها الإجراءات والقرارات الرسمية في الحكم على أن المؤسسة التعليمية قد استوفت الحدد الأدنى من متطلبات الجودة التعليمية (Fryer, 2007)، بحيث تتم إجراءات التمات الاعتماد من خلال

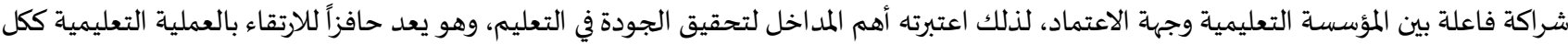
(مجيد والزيادات، 2008).

ويرى بوريس (Burris, 2008) أن الاعتماد التربوي هو عملية مستمرة من الوفاء بالمعايير والتحسين المستمر وضمان الجودة، والتي يتم إثباتها من خلال

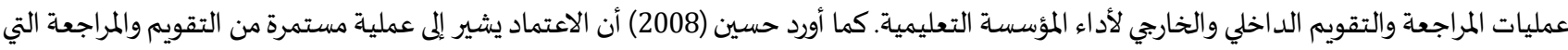

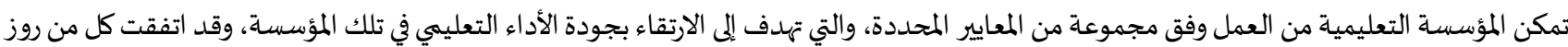

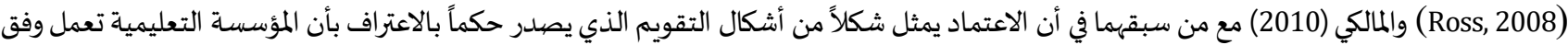
المعايير المحددة للممارسات المهنية من قبل جهة خارجية رسمية، وهو يعمل على بناء ثقة المجتمع في المؤسسة التعليمية، أما الوهيبي (Alwahaibi, 2009) فيرى أن الاعتماد التربوي هوالنتيجة النهائية لعملية التقويم التي تُظهر قدرة المؤسسة على تحقيق أهد افها من خلال تحقيقها لمعايير الجودة. 
1.2. نشأة المعاييروعلاقتها بالتقويم والاعتماد:

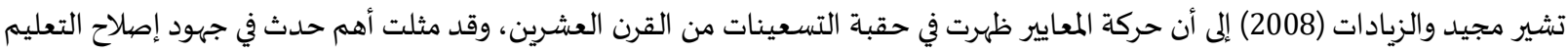

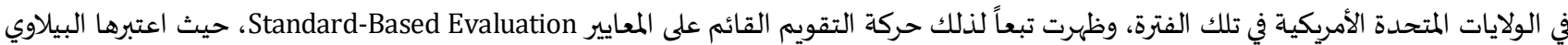
(2006) أها بمثابة عقد اجتماعي جديد في المجتمع، ينبع من الواقع، ويصف ويحدد متطلبات التعليم ويؤكد على التوقعات المرغوبة اجتماعياً من أجل التطوير والتحسين. وقد ارتبطت حركة المعايير بحركتين كبيرتين هما الجودة الشاملة والاعتماد التربوي، حيث شكلت الحركات الثلاث فكراً تربوياً مترابطاً في تلك الفترة أيضاً، وأصبحت المعايير هي المدخل الحقيقي لتحقيق جودة التعليم والنهوض بالمخرجات، بينما مثلّلَ الاعتماد الشهادة التي تؤكد بأن المؤسسة

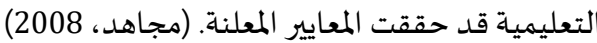
لذا تعتبر المعايير Standards الركيزة الرئيسية في عملية تقويم الأداء المدرسي للحصول على الاعتماد، وهي تمثل أحد العناصر الرئيسية الثلاثة في عملية التقويم بصفة عامة (الوصف، والمعايير، وإصدار الحكم)، حيث لا يمكن أن تتم عملية التقويم إلا بالرجوع إلى المعايير التي تحدد الممارسات التربوية التي ينبغي توافرها في العمل المدرسي (Hoss, 2008) (إلى أن المعايير يجب أن تمثل أفضل الممارسات المهنية الجيدة التي تحقق مستوى (Hannigan, 2008) وتشير رون الإنجاز المرغوب من الطلبة، ويتفق معها هيرمان (Herman, 2009) في أن بناء وتطوير المعايير التربوية يجب أن يقوم على استقاء أفضل الممارسات العملية المطلوبة، ولذلك ينبغي على المختصين في مجال القياس والتقويم وضع المعايير بحيث تتناسب مع قدرات وإمكانات من سيتم تقويمههم في ضوئها، والحرص على مئى

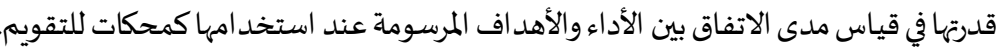
ويرى النبوي (2006) أن الهدف من المعايير هو وجود إطار موحد يمكّن جميع المدارس من تحقيق نفس التوقعات المتعلقة بأداء الطلبة، مع الوعي

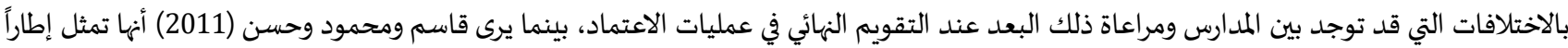
مرجعياً يتم على أساسها بناء المؤشرات ومقاييس التقدير، وبناء الأدوات لقياس وتقويم أداء المدارس، فمن خلالها يمكن إحداث نقلة نوعية في مدخلات

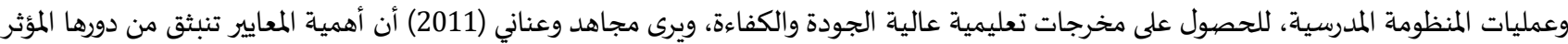
والفعَال في عمليات تقويم أداء المؤسسات التعليمية، فهي تمد المختصين في الشأن التربوي بمعلومات وبيانات دقيقة ومتسقة عن أداء المؤسسات. فهي كما ذكر المؤرخ التربوي رافيتش Ravitch (المشار إليه في أوشي (2007)) بأنها ضرورية لتحقيق التميز وعدالة الفرص التعليمية وتقنين الممارسات الصحيحة للعمل المدرسي. وقد أورد كل من عباس (2003)، ومخلوف (2007) عدد من الخصائص التي ينبغي توفرها في المعايير، أهمها: أن تكون صهادقة، وثابتة، ومرنة، وواقعياة، وقابلة للقياس، وشاملة لكافة جوانب العملية التعليمية والتربوية والسلوكية، كما يراعى فهها التناسب بين الأداء المتوقع والأهداف المرسومة،

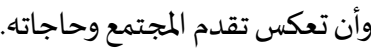

2.2. المؤشرات وعلاقتها بالمعايير:

تمثل المؤشرات Indicators المستوى الأكثر تحديداً للمعايير، حيث تصاغ في عبارات إجرائية واضحة قابلة للقياس، تمكّن من الحكم على مقدار ما يتحقق من المعايير، وقد عرّفها عبد الرسول (2005) على أنها "عبارات تصف الأداء أو السلوك المتوقع من الأفراد أو المؤسسات للوفاء بمتطلبات تحقيق المعيار"

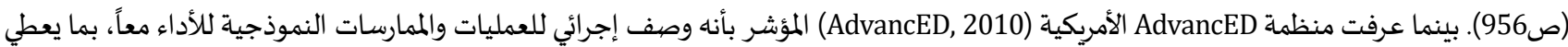

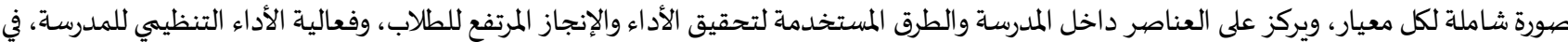

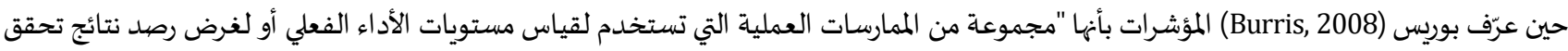
المعيار" (ص8).

ويرى كل من علام (2007)، وعودة (2011) أن مؤشرات الأداء ترتبط بشكل عام بعملية التقويم التي لا يمكن أن تتم إلا بوجود إطار متكامل من

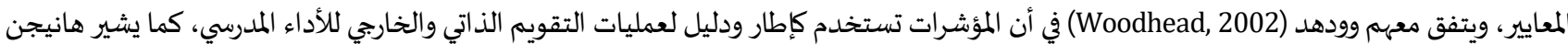
(Hannigan, 2008) يتوجب القيام بها، وبالتالي فهي تمثل مجموعة الإجراءات التي يتم تحقيق المعيار بواسطتها. فالمعايير هي بمثابة التوقعات المرجوة من العمليات التعليمية التعلمية في المدارس، بينما المؤشرات توفر وسائل متعددة لتطبيق المعايير، لذا يجب أبهات أن

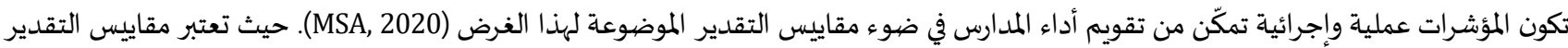

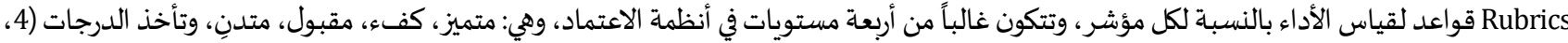

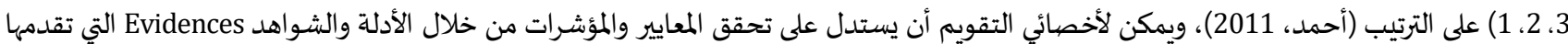
المدرسة أثناء عملية التقويم الخارجي ضهمن عمليات الاعتماد. 


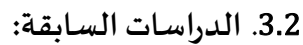

يستعرض هذا الجزء من البحث بعضاً من الدراسات السابقة ذات الصلة بمعايير التقويم والاعتماد المدرسي؛ حيث ركز الباحثون أهمية التعرض للدراسات التي نفذت في البيئة العُمانية والعربية وكذلك الأجنبية، وهي معروضة بحسب أبحسب التسلسل الزمني من الأقدم للأحدث. أجرى فيرتج (Fertig 2007) دراسة هدفت إلى معرفة واقع اعتماد المدارس الدولية وكيفية توظيف معايير الاعتماد؛ حيث قام الباحث بمراجعة وتحليل تقارير (88) مدرسة تم اعتمادها من قبل رابطة الدول المستقلة بأوروبا، وقد توصلت الدراسة إلى أن العاملين بالمدارس يطالبون في تقاريرهم بوضع

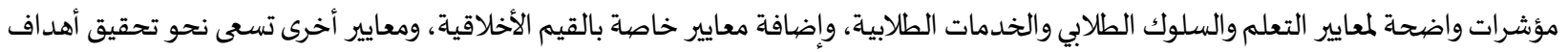

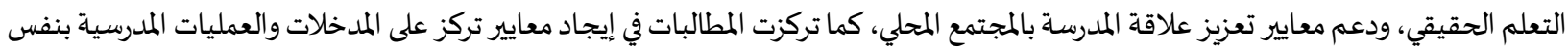

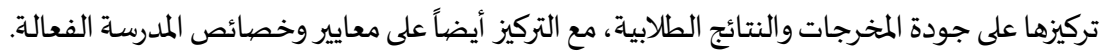
أما دراسة فيتش (Fisch, 2010) فقد هدفت إلى فحص الأسلوب النوعي في تقويم المدارس ضمدمن عمليات الاعتماد باستخدام ملف التوثيق للمدرساة،

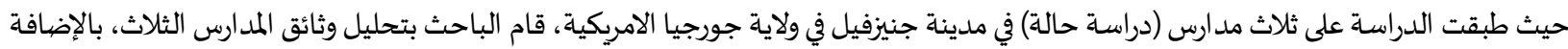
إلى إجراء مقابلات مع عدد من العاملين بالمدارس والطلاب وأولياء أمورهم، وتحليل بعض أعمال الطلبة. وقد توصلت الدراسة إلى أهمية استخدام

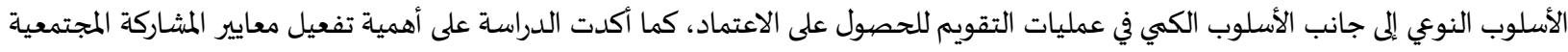

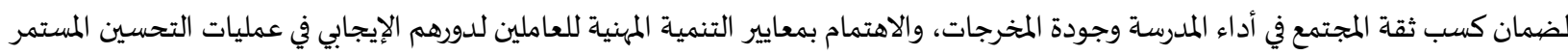
لكلأداء المدرسي. وقامت النعُمانية (2010) بإجراء دراسة هدفت إلى معرفة واقع تطبيق معايير تقييم الأداء المدرسي في مدارس سلطنة عُمان ومدى تغطيتها لكافة عناصر

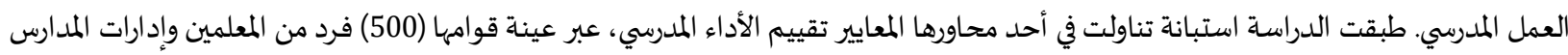
من الجنسين. وقد توصلت الدراسة إلى ارتفاع درجة تطبيق معايير تقييم الأداء المدرسي، وبالرغم من ذلك إلا أن هناك بعض الصنيه الصعوبات التي واجهت

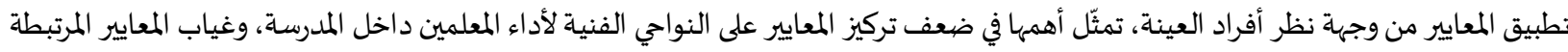

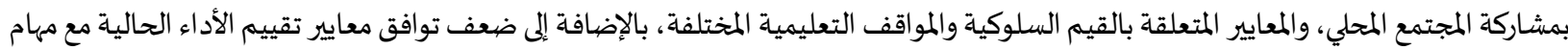
العاملين بالمدرسة.

بينما هدفت دراسة ساونديرس (Saunders, 2010) إلى بيان أهمية تحديد نتائج تعلم الطلبة كأحد مؤشرات معايير الاعتماد، والتركيز على مراجعة وتدقيق أعمال الطلبة في عمليات التقويم الذاتي للتاكد من مستويات انجازهم للمعارف والمعلومات والخبرات المكتسبة، قامت الباحثاتة بتحليل باتيل بيانات

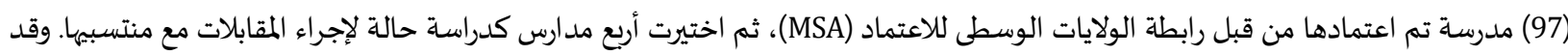

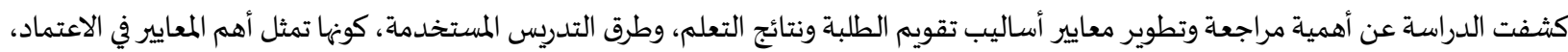

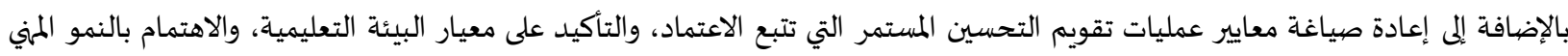

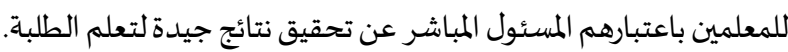
أما دراسة المالكي (2010) فقد هدفت إلى وضع تصور بالمعايير المقترحة للاعتماد الأكاديمي في مدارس التعليم الثانوي العام للبنات بمحافظة جدة، من

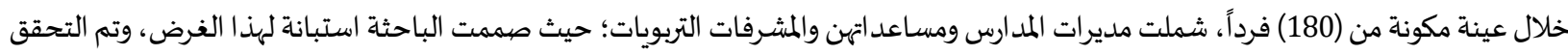

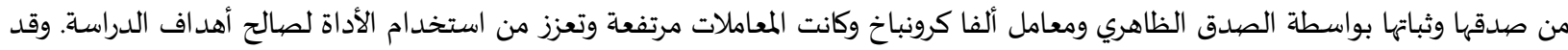

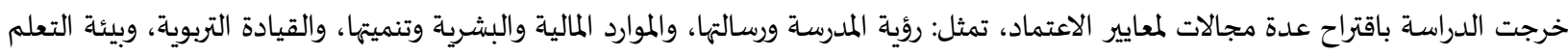

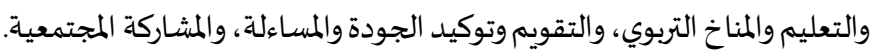

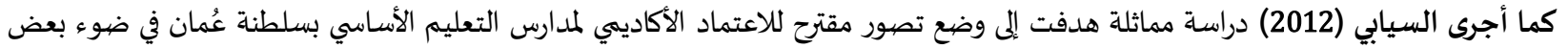

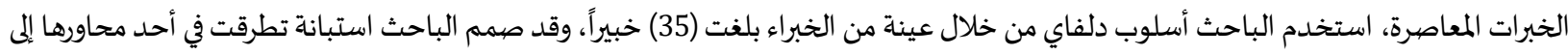
مجالات الاعتماد. وقد توصل الباحث إلى اقتراح (13) مجالاً لمعايير الاعتماد دون التطرق إلى صياغة المعايير أو تحديد مؤشراتها، شملت هذه المجالات:

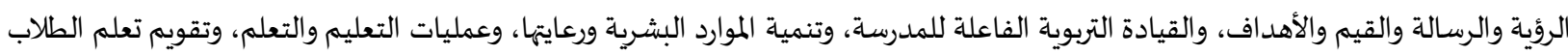

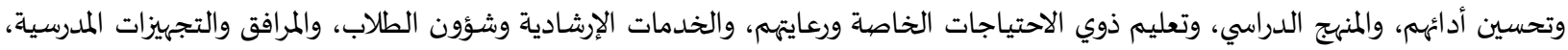

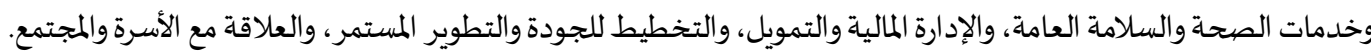

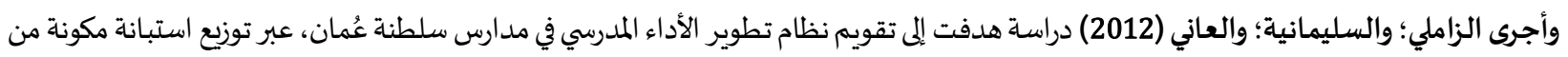

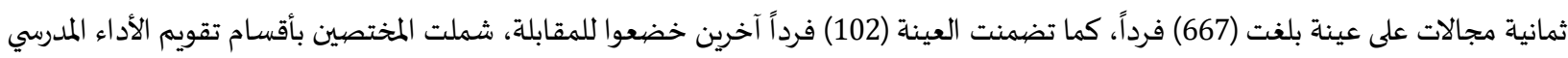
وعدد من مديري المدارس والمعلمين والطلاب وأولياء الأمور في (3) محافظات تعليمية (جنوب الباطنة، والداخلية، وظفات وظفار). وتوصلت الدراسة إلى وجود 
قصهور في تغطية المعايير الحالية لكافة عناصر الأداء المدرسي، لذلك أوصت الدراسة بأهمية إضافة عناصر أكبر وأشمل للنظام مثل مشاركة المجتمع المحلي في تحسين وتطوير أداء المدارس، وتحسين نوعية الأنشطة المدرسية المصاحبة للمناهج الدراسية، واستخدام الأساليب الحديثة للتقويم في المدارس.

أما ماتي (Mattei, 2012) فقد أجرت دراسة تحليلية مقارنة هدفت إلى تحديد التباين في المستويات التعليمية بين طلاب المدارس الابتدائية والمتوسطة

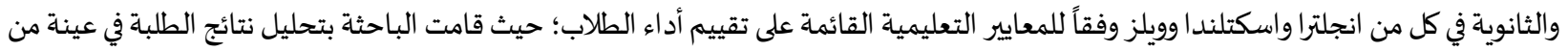
مدارس الدول الثلاث في الفترة ما بين 1988-2009م في اختبارات اللغة والرياضيات والعلوم. وقد توصلت الدراسة إلى عدد من النتائج؛ أهمها أن تطوير

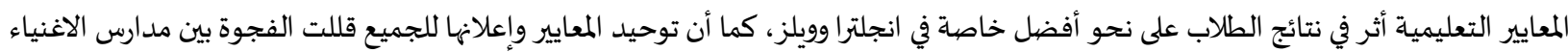
والفقراء. أيضاً توصلت الدراسة إلى أهمية تعزيز معايير الخدمات الاجتماعية المقدمة للطلبة الماتي، وتعزيز المساواة في الفرص التعليميلة، ودعم معايير التمويل

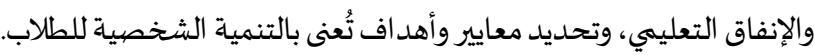
وجاءت دراسة عايش (2017) بهدف الكشف عن درجة توفر معايير الاعتماد والجودة في المدارس الخاصة بمحافظة غزة، عبر تطبيق استبانة تكونت من

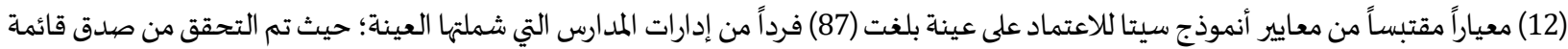

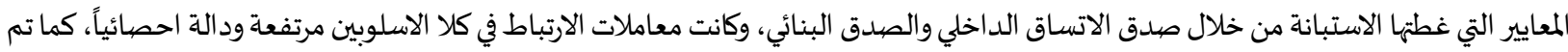
التأكد من ثبات الأداة بواسطة معامل ألفا كرونباخ وطريقة التجزئة النصفية، وكانت معاملات الثبات عالية ومقبولة تعزئة من صححة المعايير المستخدمة

في التقويم والاعتماد. وقد كشفت نتائج الدراسة عن توافر المعايير بدرجة مرتفعة، نظراً لاهتمام المدارس الخاصة وادية وحرصهيا على تطبيق معايير الجودة.

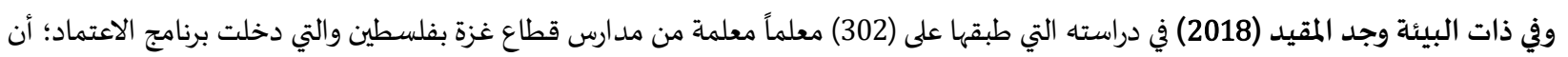
هناك حرصا كبيراً على تطبيق معايير الاعتماد المدرسي، نظراً لقناعة العينة بأهميتها في تجويد أداء المدرسة وإدارة الموارد، واهتماما منهم برفع نواتج تعلم

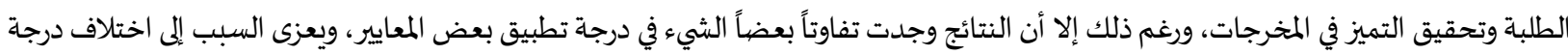
وضهوحها وقدرة المعلمين على تطبيقها. وقد أوصت الدراسة بضرورة تقييم المعايير وتطويرها حسب المستجدات واتهات والتركيز على المعايير الخاصة بنمو

شخصية الطالب في كافة جوانها.

وكشفت دراسة أبو رحمة (2018) عن إمكانية تطبيق معايير نموذج سيتا للاعتماد المدرسي بدرجة كبيرة في المدارس الحكومية بالمحافظات الجنوبية بفلسطين، عبر عينة بلغت (249) من مديري ومديرات تلك المدارس؛ حيث طبق الباحث استبانة شملت (7) معايير للنموذج المقترح، وللتحقق من صداق

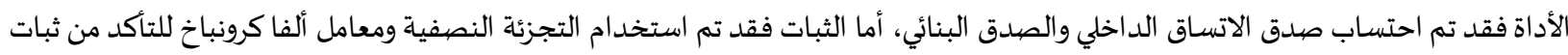
المعايير، فكانت مؤشرات الصدق والثبات عالية وتسمح باستخدام القائمة لأغراض التقويم والاعتماد. وقد أوصت عينة الدراسة بضرورة الطيات تطوير معايير وطنية خاصةة تراعي الخصوصية الفلسطينية وتلبي تطلعاتها التعليمية. وعلى نفس المسارجاءت نتائج دراسة عودة (2020) متوافقة مع سابقتها؛ حيث هدفت إلى إمكانية تطبيق معايير الاعتماد المدرسي لدولة قطر في المدارس

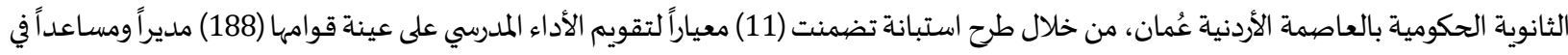

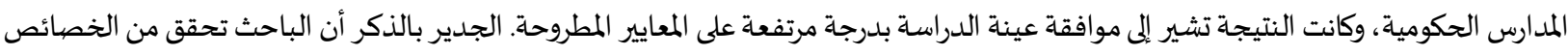

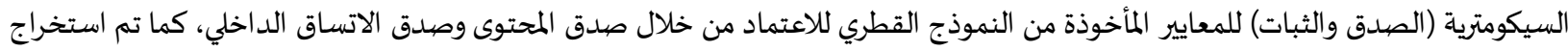

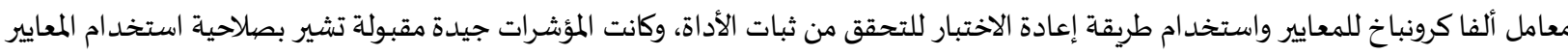

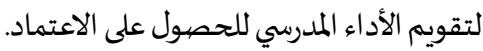
وتوصلت دراسة الربادي (2020) إلى أن درجة توفر معايير الاعتماد المدرسي في المدارس الأهلية باليمن جاءت بدرجة متوسطة إلى عالية، ويعود السبب

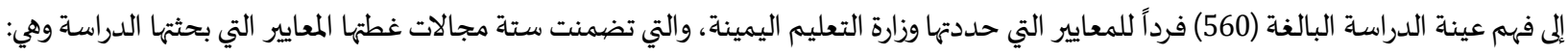

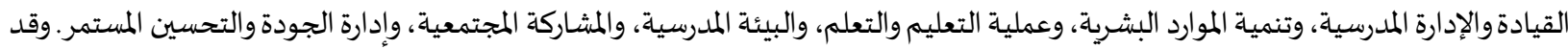

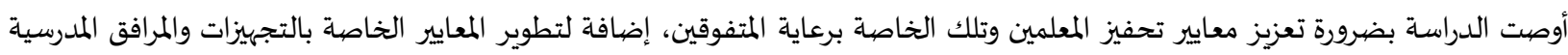

وتكنولوجيا المعلومات.

التعقيب على الدراسـات السابقة:

في ضوء ما تم عرضها يلاحظ أن بعض الدراسات المحلية تطرقت إلى تقويم نظام تقويم وتطوير الأداء المدرسي بسلطنة عُمان كدراسة النعُمانية (2010)،

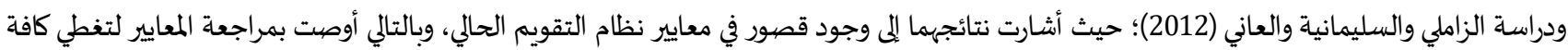
جوانب العمل المدرسي، والعمل على استحداث أساليب حديثة لتقويم المدارس، وهذا ما تهدف إليه الدراسة الحالية حول بحثها في بناء معايير للتقويم والاعتماد المدرسي، وهو الأسلوب البديل للتقويم الشامل للأداء المدرسي. وفي ذات المنحى جاءت الدراسات التي طبقت في بيئات أجنبية كدراسات كل من فيرتج (Fertig, 2007) 
وفيتش (Fisch, 2010) وساونديرس (Saunders, 2010) وماتي (Mattei, 2012) جاءت متفقة حول أهمية أن تغطي معايير التقويم والاعتماد كافة جوانب الأداء المدرسي وعدم إغفال الجوانب السلوكية والشخصية المرتبطة بالطالب، والتركيز على نتائج الطلبة باعتبارهم أهم مخرج في العملية التعليمية، إضافة لأهمية إدراج معايير تتعلق بالتنمية المهنية للمعلمين ومعايير التطوير والتحسين المدرسي ضيمن قائمة معايير الاعتماد. أما الدراسات التي طبقت في بيئات عربية فقد جاءت متفقة في بعض أهدافها مع أهداف الدراسة الحالية في اقتراح معايير للتقويم والاعتماد المدرسي،

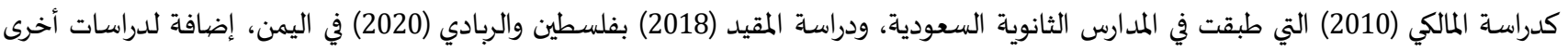
اشتركت في ذات الهدف إلا أنها استندت على تطبيق معايير جاهزة مقتبسة من معايير نموذج سيتا كدراسة عايش (2017) وأبو رحمة (2018) التي نفذت في البيئة الفلسطينية، وأخرى اعتمدت على تطبيق معايير النموذج القطري كما في دراسة عودة (2020) بالأردن، بينما في سلطنة عُمان لم يجد الباحئ البئين سوى

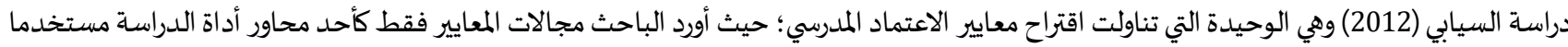
أسلوب دلفاي في تحديدها، ولم يتطرق إلى صياغة المعايير أو تحديد مؤشراتها، وهذا ما يبرر إجراء الدراسة الحالية التي تتميز في تركيزها على بناء المعايير وصياغتها بطريقة محددة، ووضع مؤشرات إجرائية لكل معيار قابلة للقياس والتقويم، كما تميزت في إيجادها للخصائص السيكومترية لهذه المعايير (الصدق لهات والثبات) بعدة طرق إحصائية مختلفة من خلال تطبيقها الميداني لأداة الدراسة.

3.

1.3. مجتمع الدراسة وعينتها:

طبقاً لإحصائيات وزارة التربية والتعليم تألف مجتمع الدراسة من (2127) فرداً من المشرفين الإداريين ومشرفي تقويم الأداء المدرسي، ومديري ومديرات مدارس الحلقة الثانية ومساعديهم، إضافة للمعلمين والمعلمات الأوائل في مدارس كل من المحافظات التالية: مسقط، وشمال الباطنة، والداخلية، وشمال الشرقياة، ومحافظة ظفار، بالإضافة إلى المشرفين الإداريين التابعين لديوان عام الوزارة. وقد تم اختيار عينة عشوائية طبقية بلغ عدد أفرادها (490) فرداً،

شكلت نسبة (23\%) من مجتمع الدراسة. وجدول (1) يوضح توزيع أفراد عينة الدراسة.

\begin{tabular}{|c|c|c|c|c|c|c|c|c|c|}
\hline \multicolumn{2}{|c|}{ المجموع } & \multicolumn{6}{|c|}{ المحافظات } & \multirow[t]{2}{*}{ النوع } & \multirow[t]{2}{*}{ الوظيفة } \\
\hline النسبة & العدد & الوزارة & ظفار & شمال الشرقية & الداخلية & شمال الباطنة & مسقط & & \\
\hline$\% 9$ & 43 & 11 & 7 & 4 & 8 & 11 & 2 & ذكور & \multirow[t]{2}{*}{ مشرفون } \\
\hline$\% 5$ & 25 & 4 & 5 & 2 & 6 & 2 & 6 & إناث & \\
\hline$\% 17$ & 83 & - & 15 & 13 & 19 & 20 & 16 & ذكور & \multirow[t]{2}{*}{ إداريون } \\
\hline$\% 20$ & 97 & - & 16 & 12 & 20 & 23 & 26 & إناث & \\
\hline$\% 24$ & 119 & - & 11 & 21 & 28 & 41 & 18 & ذكور & \multirow[t]{2}{*}{ معلمون أوائل } \\
\hline$\% 25$ & 123 & - & 19 & 22 & 25 & 31 & 26 & إناث & \\
\hline \multicolumn{2}{|c|}{490} & 15 & 73 & 74 & 106 & 128 & 94 & العدد & \multirow[t]{2}{*}{ المجموع } \\
\hline \multicolumn{2}{|c|}{$\% 100$} & $\% 3$ & $\% 15$ & $\% 15$ & $\% 22$ & $\% 26$ & $\% 19$ & النسبة & \\
\hline
\end{tabular}

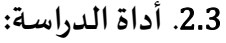

تمثلت أداة الدراسة في تصميم استبانة تضمنت قائمة بمعايير التقويم والاعتماد المدرسي؛ حيث تم بناؤها وفقا للخطوات الآتية: مسح وتحليل الأدبيات التربوية المرتبطة بمعايير الاعتماد المدرسي وتقويم الأداء المدرسي بشكل عام. العمل على تحليل بعض النماذج العالمياة للاعتماد المدرسي، بالإضافة إلى معايير بعض الدول العربية والخليجية، واستخلاص أهم المكونات المشتركة فيما

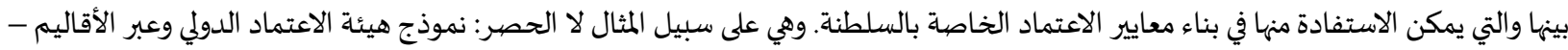
سيتا Commission on International and Trans-regional Accreditation-CITA الكليات والمدارس Middle States Association Of Colleges And Schools -MSA (2020)، ونموذج منظمة AdvansED الأمريكية للاعتماد المدرسي

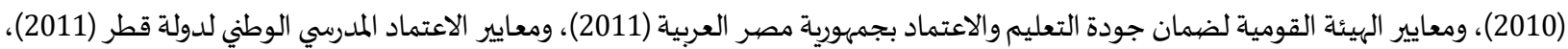
ومعايير الاعتماد المدرسي لدولة الامارات العربية المتحدة (2011)، إضافة لبعض المضيكهان المعايير المقترحة في الدراسات العربية والأجنبية السابقة. مراجعة معايير السلطنة التي تختص بالأداء المدرسي، كالتي تضمنها دليل مشروع تطوير الأداء المدرسي (2009). اشتقاق المعايير التي تمثل أفضل الممارسات التربوية التي تتلاءم مع البيئة التعليمية والمدرسية في المدارس الحكومية بسلطنة عُمان. 
3.3. وصف الأداة:

تكونت الأداة في صورتها الأولية من (10) معايير و(127) مؤشرا إجرائياً، يجاب عنها باستخدام تدرج خماسي حسب مقياس ليكرت Likert، لتقدير

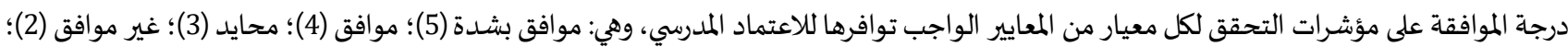
وغير موافق بشدة (1). كما اشتملت الاستبانة على بعض المعلومات الخاصية بالمستجيبين.

4.3 إجراءات الدراسة:

مرت إجراءات الدراسة بخطوات رئيسية وهي على النحو الآتي:

أولاً: للتحقق من الخصائص السيكومترية الأولية للأداة تم اتخاذ الإجراءات التئئ الآتية:

1. تم التحقق من الصدق الظاهري للأداة (قائمة المعايير والمؤشرات) من خلال عرضهيا على مجموعة مكونة من (22) عضواً من أساتذة كلية التربية

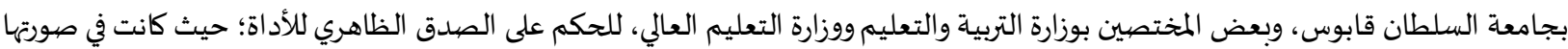
الأولية مكونة من (10) أبعاد و(127) فقرة، حيث طلب منهم إبداء آرائهم ومقترحاتهم في أبعاد الأداة وفقراتها ومدى وضيوحها، وأيضاً ارتباط الفقرات

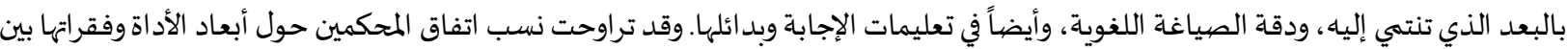
(84\%-100\%)، حيث تم إلغاء (44) فقرة، وتعديل صياغة (8) فقرات، وأصبحت الأداة في صورتها الهائية مكونة من (10) معايير تمثل أبعاد أداة

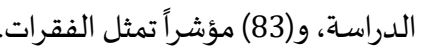

2. تم التطبيق على عينة استطلاعية عشوائية مكونة من (78) فرداً، كما تم إعادة التطبيق على بعض أفرات الفراد العينة الاستطلاعية والذين بلغ عددهم (36) فرداً بعد اسبوعين من التطبيق الأول، لاستكمال إجراءات حساب الثبات.

ثانياً: التطبيق الفعلي للأداة على العينة الكلية للدراسة: 1. بعد التأكد من صدق الأداة وثباتها وصلاحيتها للتطبيق واستبعاد العينة الاستطلاعية من العينة الكلية، تم تطبيق الأداة على العينة الفعلية للدراسة والتي بلغت في عددها الهائي (490) فردًا. 2. استمرت مدة التطبيق قرابة الشهر للحصول على عدد كاف من الاستجابات والتي تسمح بإجراء التحليل العاملي التوكيدي للتحقق من الخصائص السيكومترية لقائمة المعايير المقترحة.

5.3. المعالجة الإحصائية: تمت معالجة البيانات بناءً على طبيعة الدراسة وأسئلتها من خلال توظيف برنامج الرزمة الإحصائية SPSS لإدخال البيانات وتحليلها، كما تم توظيف الأساليب الإحصائية التالية: معامل ارتباط بيرسون لحساب الارتباط بين درجة الفقرة ودرجة البعد المنتمية إليه، وارتباطها بالدرجة الكلية، وأيضاً الارتباط بين الأبعاد المكونة

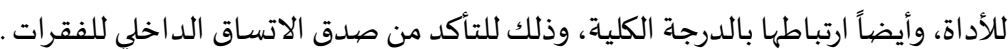
التحليل العاملي التوكيدي باستخدام برنامج أموس AMOS 7.0 للتحقق من الصدق العاملي للأداة. تم استخدام معامل ألفا كرونباخ Cronbach's Alpha لحساب معاملات الثبات لكل من أبعاد أداة الدراسة وكذلك للأداة ككل. معامل ارتباط بيرسون للتأكد من ثبات الأداة بطريقة إعادة الاختبار Test-Retest .

\section{4. نتائج الدراسة ومناقشتها}

1.4. نتائج السؤال الأول: والذي ينص على "ما قائمة المعايير المقترحة للتقويم والاعتماد المدرسي للمدارس الحكومية بسلطنة عُمان؟". في ضوء ما تم مراجعته في الأدب النظري ونماذج التقويم والاعتماد المدرسي المختلفة سواءً العالمية أو العربية والخليجية، إضافة للمعايير التي وردت في

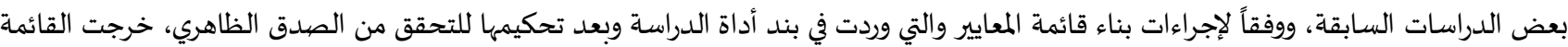
بالمعايير الآتية والموضحة بجدول (2) حسب الأبعاد وعدد المؤشرات. بلتاء

\begin{tabular}{|c|c|c|c|}
\hline عدد المؤشرات & صيغة المعايير & الأبعاد (المعاير) & r \\
\hline 8 & للمدرسة رؤية ورسالة واضحة تتجسد معانها في خطة المدرسة وأهدافها. & $\begin{array}{l}\text { (التروية والرسالة والخطة الاستراتيجي } \\
\text { (التخطية }\end{array}$ & 1 \\
\hline 12 & تنظيمها، بما يحقق أهداف الخطا إدارة مواردها بفاعلية، وتعمل على تطويرها وتحسينها وحسن & (البشرية والمادية) - (إدارة الموارد & 2 \\
\hline
\end{tabular}




\begin{tabular}{|c|c|c|c|}
\hline \multirow[t]{2}{*}{5} & تسعى المدرسة إلى ترسيخ مبادئ المواطنة المسؤولة وتوطيد العلاقات المجتمعية مع أفراد & المشاركة المجتمعية & 4 \\
\hline & المجتمع المحلي ومؤسساته المختلفة. & & \\
\hline \multirow[t]{2}{*}{8} & تعمل المدرسة على استثمار الممبنى المدرسي بصورة مناسبة، كما تحقق مستويات عالية من & المبنى المدرسي وإجراءات الأمن والسلامة & 5 \\
\hline & اشتراطات الأمن والسلامة داخل مرافقها. & & \\
\hline \multirow[t]{2}{*}{10} & تؤكد المدرسة على توظيف استراتيجيات وطرق تدريس فاعلة تخدم المنهج الدراسي & المنهج الدراسي وطرق التدريس المتبعة & 6 \\
\hline & وتحقق الأهداف التعليمية المرسومة. & & \\
\hline \multirow[t]{2}{*}{8} & تحرص المدرسة على توظيف أساليب التقويم المعتمدة من الوزارة بطريقة فعالة لتحقيق & أساليب تقويم التحصيل ونتائج الطلبة & 7 \\
\hline & نتائج متميزة في تحصيل الطلبة & & \\
\hline \multirow[t]{2}{*}{7} & تهتم المدرسة بإثراء مصادر التعلم والمختبرات وتنظيم مرافقها وتوظيفها بما يخدم العملية & 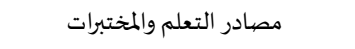 & 8 \\
\hline & 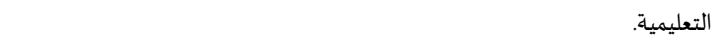 & & \\
\hline \multirow[t]{2}{*}{10} & تقدم المدرسة خدمات وأنشطة متنوعة تساعد على تحقيق النمو في الجوانب المختلفة & الخدمات الطلابية والأنشطة المدرسية & 9 \\
\hline & 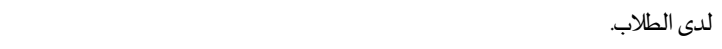 & & \\
\hline \multirow[t]{3}{*}{8} & تسعى المدرسة من خلال فريق التطوير والتحسين إلى نشر ثقافة الجودة بين العاملين من & خطة التحسين المدرسية & 10 \\
\hline & أجل التحسين المستمر لكافة مجالات العمل المدرسي بما يحقق مستويات عالية للأداء & & \\
\hline & الفعلي. & & \\
\hline 83 & & 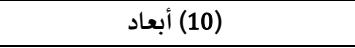 & \\
\hline
\end{tabular}

2.4. نتائج السؤال الثاني: والذي ينص على "ما مؤشرات صدق قائمة معايير التقويم والاعتماد المدرسي للمدارس الحكومية بسلطنة عُمان؟؟".

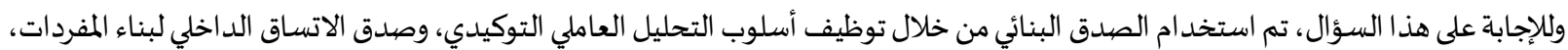
وذلك على النحو الآتي:

• التحليل العاملي التوكيدي Confirmatory Factor Analysis: للتحقق من البنية العاملية لقائمة معايير الاعتماد المدرسي تم إجراء التحليل

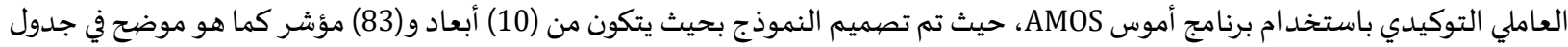

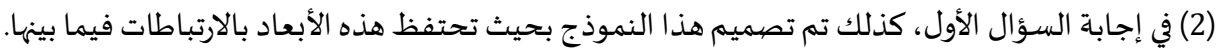
وقد أظهر نموذج التحليل العاملي التوكيدي تطابقه مع بيانات الدراسة الحالية وذلك بعد حذف (5) فقرات من أبعاد النال النموذج بسبب انخفاض قيم تشبعها

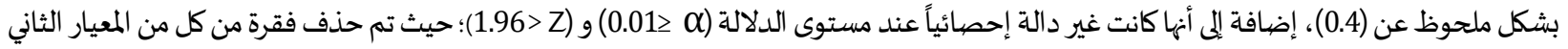

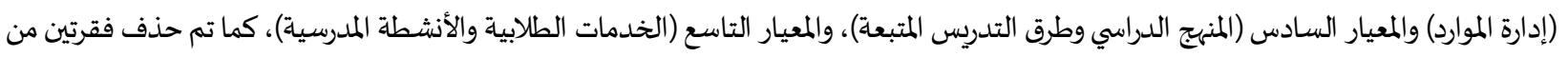

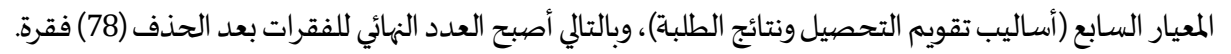

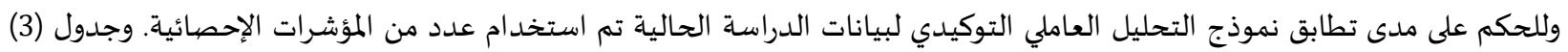
يوضح هذه المؤشرات، وأسباب اختيارها والحدود الدنيا للقيم المقبولة. جدول (3): مؤشرات حسن المطابقة لقائمة معايير التقويم والاعتماد المدرسي

\begin{tabular}{|c|c|c|c|c|}
\hline التحليل الحالي & القيمــة المقبولة* & سبب اختياره & 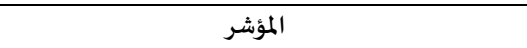 & 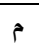 \\
\hline 2.3 & 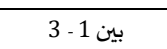 & أقل اعتماداً على حجم العينة & اختبار مربع كاي النسبى Chi- ( & 1 \\
\hline 0.05 & أقل من 0.06 & أقل اعتماداً على حجم العينة وأقل & $\begin{array}{c}\text { Squared } \\
\text { Root الجذر التربيعى المتوسط مربعات خطارب (RMSEA) } \\
\text { Mean Square Error of Approximation }\end{array}$ & 2 \\
\hline 0.04 & أقل من 0.08 & لا يتأثر بتعقد النموذج & $\begin{array}{c}\text { الجذر التربيعى لمتوسطات مربعات البواقي المعيارية } \\
\text { Standardized Root Mean Square Residual } \\
\text { (SRMR) }\end{array}$ & 3 \\
\hline 0.87 & أكبر من 0.9 & لا يتأثر بحجم العينة & مؤشر المطابقة المقارن & 4 \\
\hline 0.86 & أكبر من 0.9 & لا يتأثر بتعقد النموذج & $\begin{array}{l}\text { Non-normed Fit مؤشر المطابقة غير الممعياري) } \\
\text { Index(NNFI) } \\
\text { (Thompson, 2004; Sun, 2005)* }\end{array}$ & 5 \\
\hline
\end{tabular}

يلاحظ من جدول (3) أن مؤشرات حسن المطابقة للتحليل الحالي بعد حذف الفقرات قد حققت قيماً مقبولة، حيث بلغت قيمة مربع كاي النسبي

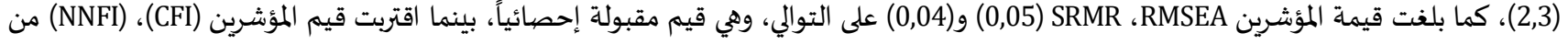

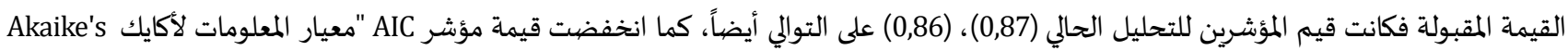
Information Criterion

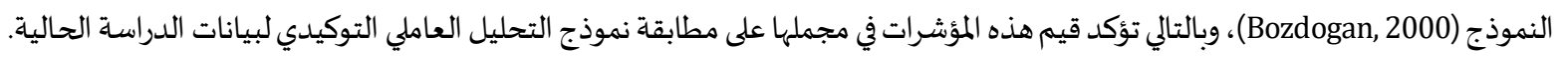


وفي التحليل العاملي التوكيدي يمكن الحكم على مدى تشبع الفقرة على البعد المنوط بها قياسـه من خلال قيم بيتا المعيارية م، ولا توجد قيمة محددة يمكن عندها قبول أو رفض مستوى تشبع الفقرة على البعد (Byrne, 2010)، وذلك لأن التحليل العاملي التوكيدي يستخدم قيم القيمة الحرجة Critical Ratio

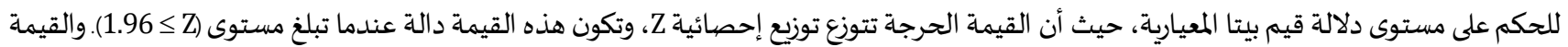
الحرجة هي حاصل قسمة قيمة بيتا الغير معيارية للفقرة على الخطأ المعياري لتقدير قيمة بيتا غير المعياري (Kline, 2010). وجدول (4) يوضح قيم بيم بيتا غير المعيارية والخطأ المعياري والقيمة الحرجة وقيم بيتا المعيارية للفقرات على أبعاد أداة الدراسة.

جدول (4): قيم بيتا غير المعياربة والخطأ المعياري والقيمة الحرجة وقيم بيتا المعيارية للفقرات على أبعاد أداة الدراسة

\begin{tabular}{|c|c|c|c|c|c|c|c|c|c|c|c|}
\hline \multicolumn{11}{|c|}{ الفقرات } & \multirow{2}{*}{ لبعدوشرات البعد } \\
\hline & & & 8 & 7 & 6 & 5 & 4 & 3 & 2 & 1 & \\
\hline & & & 0.85 & 1.00 & 1.07 & 1.11 & 1.21 & 1.12 & 1.05 & 0.85 & $\beta^{*}$ \\
\hline & & & 0.07 & & 0.07 & 0.07 & 0.07 & 0.07 & 0.07 & 0.06 & S.E. \\
\hline & & & **12.14 & & **15.5 & **16.32 & **16.31 & **16.26 & **14.84 & **15.13 & C.R. \\
\hline & & & 0,50 & 0.71 & 0.73 & 0.78 & 0.77 & 0.77 & 0.7 & 0.72 & $\beta z$ \\
\hline 19 & 18 & 17 & 16 & 15 & 14 & 13 & 12 & 11 & 10 & 9 & البعد (2) \\
\hline 0.9 & 0.76 & 0.11 & 0.96 & 0.94 & 1.01 & 0.92 & 1.03 & 0.98 & 1.04 & 1.00 & $\beta$ \\
\hline 0.07 & 0.10 & 0.08 & 0.07 & 0.07 & 0.07 & 0.07 & 0.07 & 0.07 & 0.07 & & S.E. \\
\hline$* * 13.1$ & $* * 7.6$ & **13.84 & **14.19 & $* * 14.09$ & $* * 13.6$ & **13.26 & **14.96 & **14.19 & **14.61 & & C.R. \\
\hline \multirow[t]{42}{*}{0.64} & 0.53 & 0.68 & 0.70 & 0.70 & 0.67 & 0.65 & 0.75 & 0.70 & 0.73 & 0.67 & $\beta z$ \\
\hline & & & & 26 & 25 & 24 & 23 & 22 & 21 & 20 & البعد (3) \\
\hline & & & & 1.00 & 1.10 & 1.22 & 1.33 & 1.05 & 1.12 & 0.98 & $\beta$ \\
\hline & & & & & 0.07 & 0.08 & 0.08 & 0.07 & 0.07 & 0.07 & S.E. \\
\hline & & & & & **15.69 & $* * 15.28$ & **15.95 & **15.32 & **15.31 & **13.89 & C.R. \\
\hline & & & & 0.68 & 0.77 & 0.75 & 0.79 & 0.75 & 0.75 & 0.68 & $\beta z$ \\
\hline & & & & & & 31 & 30 & 29 & 28 & 27 & البعد (4) \\
\hline & & & & & & 0.81 & 0.83 & 0.87 & 0.95 & 1.00 & $\beta$ \\
\hline & & & & & & 0.06 & 0.06 & 0.06 & 0.06 & & S.E. \\
\hline & & & & & & **13.93 & **14.77 & **15.21 & **15.82 & & C.R. \\
\hline & & & & & & 0.67 & 0.71 & 0.73 & 0.76 & 0.71 & $\beta z$ \\
\hline & & & 39 & 38 & 37 & 36 & 35 & 34 & 33 & 32 & البعد (5) \\
\hline & & & 1.00 & 1.14 & 1.10 & 0.89 & 1.05 & 1.05 & 1.04 & 0.99 & $\beta$ \\
\hline & & & & 0.08 & 0.07 & 0.06 & 0.07 & 0.07 & 0.07 & 0.07 & S.E. \\
\hline & & & & **15.01 & **15.68 & **14.71 & **15.32 & **14.68 & **15.71 & $* * 14.73$ & C.R. \\
\hline & & & 0.72 & 0.70 & 0.73 & 0.69 & 0.72 & 0.69 & 0.74 & 0.69 & $\beta \mathrm{z}$ \\
\hline & & 48 & 47 & 46 & 45 & 44 & 43 & 42 & 41 & 40 & البعد (6) \\
\hline & & 1.00 & 1.25 & 1.19 & 1.07 & 0.97 & 1.10 & 1.17 & 1.01 & 0.59 & $\beta^{*}$ \\
\hline & & & 0.09 & 0.08 & 0.07 & 0.07 & 0.07 & 0.07 & 0.07 & 0.04 & S.E. \\
\hline & & & **14.53 & **15.59 & **15.31 & **14.85 & **16.19 & $* * 16.36$ & **14.71 & **14.75 & C.R. \\
\hline & & 0.70 & 0.70 & 0.75 & 0.74 & 0.71 & 0.78 & 0.79 & 0.71 & 0.49 & $\beta \mathrm{z}$ \\
\hline & & & & & 54 & 53 & 52 & 51 & 50 & 49 & البعد (7) \\
\hline & & & & & 0.92 & 1.00 & 1.15 & 1.21 & 1.13 & 0.93 & $\beta$ \\
\hline & & & & & 0.06 & & 0.07 & 0.07 & 0.07 & 0.06 & S.E. \\
\hline & & & & & **15.3 & & **16.48 & **17.42 & **15.10 & **15.44 & C.R. \\
\hline & & & & & 0.47 & 0.74 & 0.76 & 0.80 & 0.74 & 0.72 & $\beta z$ \\
\hline & & & & 61 & 60 & 59 & 58 & 57 & 56 & 55 & البعد (8) \\
\hline & & & & 0.98 & 1.08 & 1.04 & 1.10 & 1.00 & 1.00 & 1.00 & $\beta$ \\
\hline & & & & 0.06 & 0.06 & 0.06 & 0.08 & 0.06 & 0.06 & & S.E. \\
\hline & & & & **16.65 & **17.48 & **16.36 & **14.37 & **16.99 & **17.06 & & C.R. \\
\hline & & & & 0.75 & 0.78 & 0.73 & 0.65 & 0.76 & 0.76 & 0.75 & $\beta z$ \\
\hline & & 70 & 69 & 68 & 67 & 66 & 65 & 64 & 63 & 62 & البعد (9) \\
\hline & & 1.06 & 1.05 & 1.06 & 1.02 & 1.03 & 0.90 & 0.97 & 0.98 & 1.00 & $\beta$ \\
\hline & & 0.06 & 0.06 & 0.06 & 0.06 & 0.06 & 0.06 & 0.05 & 0.06 & & S.E. \\
\hline & & **18.93 & **18.26 & **18.09 & **18.42 & $* * 17.64$ & **15.82 & **17.74 & **16.94 & & C.R. \\
\hline & & 0.80 & 0.78 & 0.77 & 0.78 & 0.76 & 0.69 & 0.76 & 0.73 & 0.76 & $\beta z$ \\
\hline & & & 78 & 77 & 76 & 75 & 74 & 73 & 72 & 71 & البعد (10) \\
\hline & & & 1.00 & 1.01 & 0.97 & 0.97 & 0.95 & 0.93 & 0.93 & 0.84 & $\beta$ \\
\hline & & & & 0.06 & 0.06 & 0.06 & 0.05 & 0.05 & 0.05 & 0.05 & S.E. \\
\hline & & & & **17.34 & **17.17 & $* * 17.55$ & **18.04 & **17.88 & **17.18 & $* * 15.79$ & C.R. \\
\hline & & & 0.72 & 0.79 & 0.78 & 0.80 & 0.82 & 0.81 & 0.78 & 0.72 & $\beta z$ \\
\hline & & & & يارية & | بz & حرجة & C.R .: القيم & عياري & S.E.: الخطأ & بارية & *3: بيتا غير \\
\hline
\end{tabular}




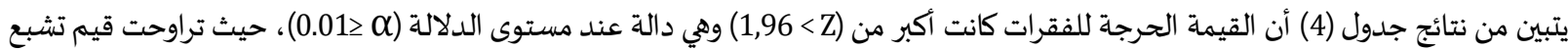

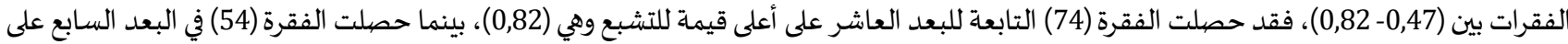
أقل قيمة للتشبع وهي (0,47). صيدق الاتساق الداخلي: تم استخدام معامل ارتباط بيرسون Pearson's Correlation لحساب معاملات الارتباط بين درجة الفقرة ودرجة البعد المنتمية إليه، وكذلك ارتباط الفقرات بالدرجة الكلية للأداة، وأيضاً تم إيجاد معاملات الارتباط بين الأبعاد المكونة للأداة، ومعاملات ارتباطها بالدرجة الكلية للأداة، وذلك للتأكد من صدق الاتساق الداخلي لبناء المفردات. وجدول (5) يوضح معاملات ارتباط الفقرات بالأبعاد المنتمية إليها وكذلك ارتباطها بالدرجة الكلية.

جدول (5): معاملات ارتباط الفقرات بالأبعاد المنتمية إليها وكذلك ارتباطها بالدرجة الكلية (ن=490)

\begin{tabular}{|c|c|c|c|c|c|c|c|c|c|c|c|}
\hline \multicolumn{11}{|c|}{ الفقرات } & الأبعاد \\
\hline & & & 8 & 7 & 6 & 5 & 4 & 3 & 2 & 1 & الأول \\
\hline & & & $* * 0.68$ & **0.78 & $* * 0.76$ & $* * 0.79$ & $* * 0.80$ & $* * 0.80$ & $* * 0.75$ & $* * 0.75$ & \\
\hline & & & $* * 0.56$ & ${ }^{* *} 0.64$ & $* * 0.67$ & $* * 0.67$ & $* * 0.66$ & $* * 0.65$ & $* * 0.61$ & ${ }^{* *} 0.60$ & *د. ك \\
\hline $\begin{array}{c}19 \\
* * 0.72\end{array}$ & $\begin{array}{c}18 \\
* * 0.67\end{array}$ & $\begin{array}{c}17 \\
* * 0.73\end{array}$ & $\begin{array}{c}16 \\
* * 0.71\end{array}$ & $\begin{array}{c}15 \\
* * 0.73\end{array}$ & $\begin{array}{c}14 \\
* * 0.72\end{array}$ & $\begin{array}{c}13 \\
* * 0.68\end{array}$ & $\begin{array}{c}12 \\
* * 0.76\end{array}$ & $\begin{array}{c}11 \\
* * 0.73\end{array}$ & $\begin{array}{c}10 \\
* * 0.75\end{array}$ & $\begin{array}{c}9 \\
* 0.70\end{array}$ & الثاني \\
\hline \multirow[t]{26}{*}{$* * 0.59$} & $* * 0.56$ & $* * 0.65$ & **0.65 & $* * 0.63$ & $* * 0.61$ & $* * 0.62$ & $* * 0.67$ & $* * 0.65$ & $* * 0.64$ & ${ }^{* *} 0.61$ & د.ك \\
\hline & & & & 26 & 25 & 24 & 23 & 22 & 21 & 20 & الثالث \\
\hline & & & & ${ }^{* *} 0.73$ & $* * 0.81$ & **0.79 & $* * 0.82$ & ${ }^{* *} 0.79$ & $* * 0.80$ & ${ }^{* *} 0.72$ & \\
\hline & & & & ${ }^{* *} 0.63$ & $* * 0.71$ & $* * 0.70$ & $* * 0.74$ & $* * 0.70$ & $* * 0.69$ & ${ }^{* *} 0.64$ & د.ك \\
\hline & & & & & & 31 & 30 & 29 & 28 & 27 & الرابع \\
\hline & & & & & & $* * 0.73$ & $* * 0.76$ & $* * 0.79$ & $* * 0.83$ & $* * 0.79$ & \\
\hline & & & & & & $* * 0.63$ & $* * 0.65$ & $* * 0.66$ & $* * 0.68$ & $* * 0.65$ & د.ك \\
\hline & & & 39 & 38 & 37 & 36 & 35 & 34 & 33 & 32 & الخامس \\
\hline & & & $* * 0.73$ & $* * 0.75$ & $* * 0.78$ & $* * 0.73$ & $* * 0.77$ & ${ }^{* *} 0.75$ & $* * 0.77$ & ${ }^{* * 0} 0.73$ & \\
\hline & & & $* * 0.69$ & $* * 0.65$ & $* * 0.67$ & $* * 0.61$ & $* * 0.61$ & $* * 0.61$ & $* * 0.65$ & ${ }^{* *} 0.62$ & د.ك \\
\hline & & 48 & 47 & 46 & 45 & 44 & 43 & 42 & 41 & 40 & السادس \\
\hline & & $* * 0.73$ & $* * 0.75$ & ${ }^{* *} 0.77$ & $* * 0.77$ & $* * 0.75$ & $* * 0.79$ & ${ }^{* *} 0.81$ & $* * 0.74$ & ${ }^{* *} 0.59$ & \\
\hline & & $* 0.68$ & $* * 0.62$ & $* * 0.66$ & $* * 0.65$ & $* * 0.60$ & $* * 0.66$ & $* * 0.70$ & $* * 0.69$ & $* * 0.59$ & د. ك \\
\hline & & & & & 54 & 53 & 52 & 51 & 50 & 49 & السابع \\
\hline & & & & & $* * 0.72$ & $* * 0.79$ & $* * 0.81$ & ${ }^{* *} 0.82$ & $* * 0.79$ & ${ }^{* *} 0.74$ & \\
\hline & & & & & $* * 0.64$ & $* * 0.62$ & $* * 0.63$ & $* * 0.70$ & $* * 0.60$ & $* * 0.64$ & د.ك \\
\hline & & & & 61 & 60 & 59 & 58 & 57 & 56 & 55 & الثامن \\
\hline & & & & ${ }^{* *} 0.78$ & ${ }^{* *} 0.81$ & $* * 0.80$ & $* * 0.76$ & $* * 0.79$ & ${ }^{* *} 0.77$ & ${ }^{* *} 0.77$ & \\
\hline & & & & $* * 0.67$ & $* * 0.68$ & $* * 0.63$ & $* * 0.55$ & $* * 0.68$ & ${ }^{* *} 0.70$ & ${ }^{* *} 0.66$ & د. ك \\
\hline & & 70 & 69 & 68 & 67 & 66 & 65 & 64 & 63 & 62 & التاسع \\
\hline & & $* * 0.82$ & $* * 0.80$ & $* * 0.80$ & $* * 0.82$ & $* * 0.80$ & $* * 0.74$ & $* * 0.78$ & $* * 0.76$ & ${ }^{* *} 0.78$ & \\
\hline & & $* * 0.74$ & $* * 0.71$ & ${ }^{* *} 0.72$ & ${ }^{* *} 0.71$ & $* * 0.70$ & $* * 0.64$ & **0.72 & $* * 0.69$ & $* * 0.73$ & د.ك \\
\hline & & & 78 & 77 & 76 & 75 & 74 & 73 & 72 & 71 & العاشر \\
\hline & & & ${ }^{* *} 0.78$ & $* * 0.82$ & $* * 0.81$ & $* * 0.82$ & $* * 0.83$ & $* * 0.83$ & $* * 0.82$ & $* * 0.77$ & \\
\hline & & & $* * 0.66$ & ${ }^{* *} 0.73$ & $* * 0.72$ & **0.73 & $* * 0.74$ & ${ }^{* *} 0.73$ & $* * 0.71$ & ${ }^{* *} 0.67$ & د.ك \\
\hline & & & عينة & : عدد أذ & & $(0,013$ & الدلالة () & ** مس & & الكلية & *د. ك: الد \\
\hline
\end{tabular}

يتضح من جدول (5) أن جميع معاملات الارتباط موجبة ودالة عند مستوى الدلالة (0) م 0.012)؛ حيث بلغ أعلى معامل ارتباط للفقرات مع البعد المنتمية إليه (0.83)، وهو معامل ارتباط الفقرة (28) المنتمية للبعد الرابع، والفقرتان (73، 74) التي تنتمي للبعد العاشر، بينما بلغ أقل معامل ارتباط (0.59)

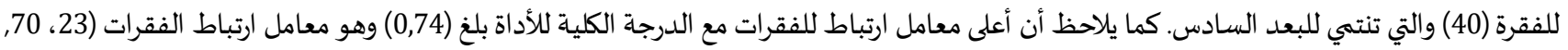

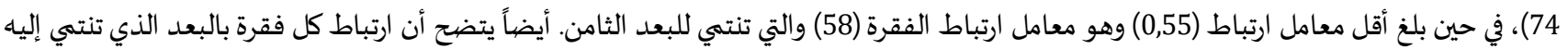
أعلى من ارتباطها بالدرجة الكلية للأداة، مما يدل على تجانس واتساق فقرات كل بعد فيما تقيساه، وهذا التجانس يعتبر مؤشرا على صدق بناء قائمة معايير الاعتماد المدرسي ومؤشراته.

أيضاً تم إيجاد معاملات ارتباط بيرسون بين الأبعاد (المعايير) العشرة المكونة للأداة، وبين الأبعاد والدرجة الكلية لأداة الدراسة، وجدول (6) يوضح ذلك. 


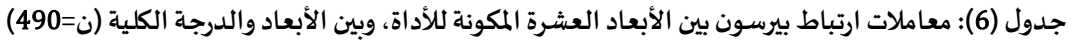

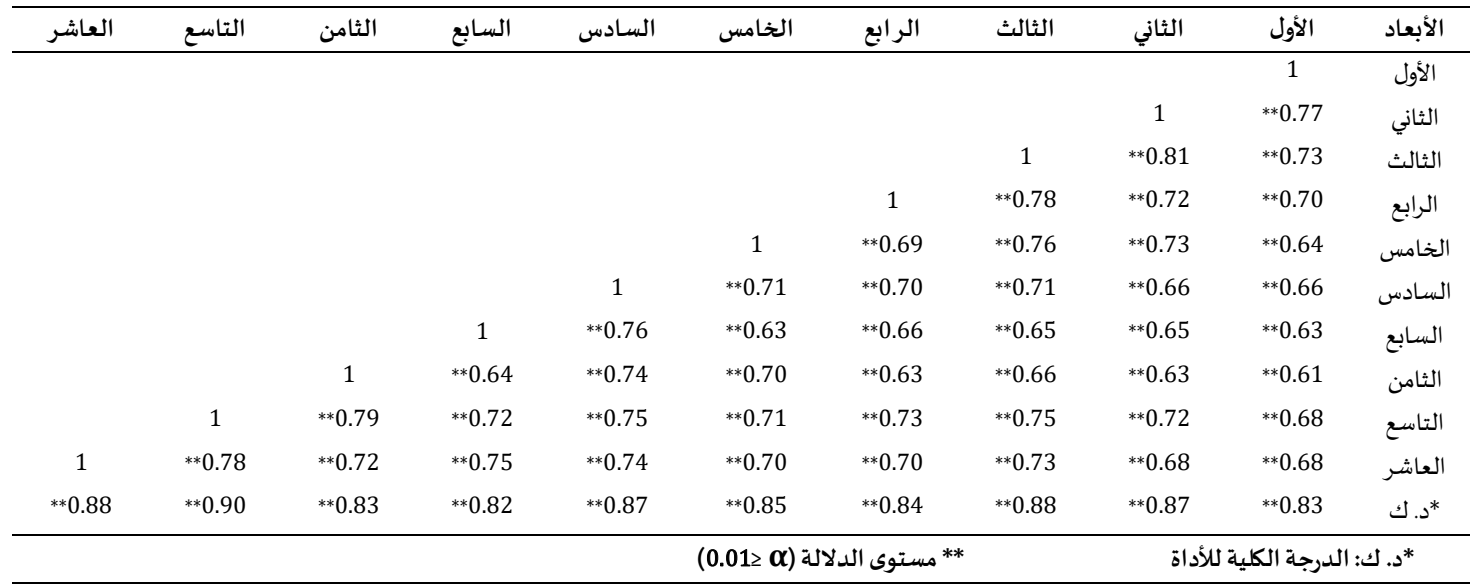

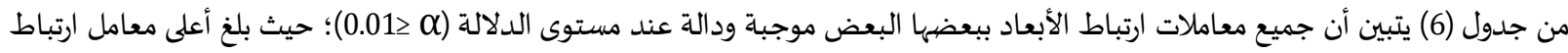

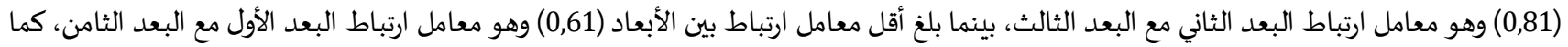

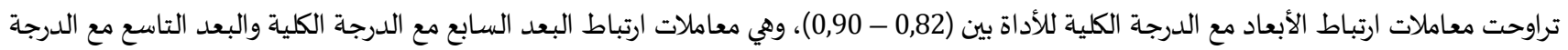

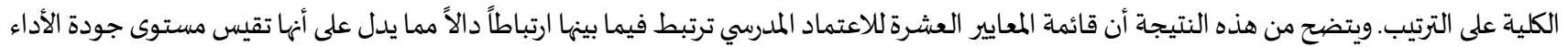
المدرسي.

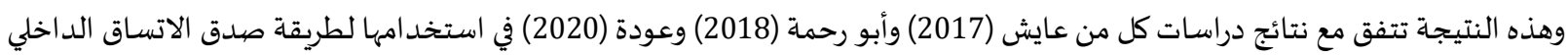

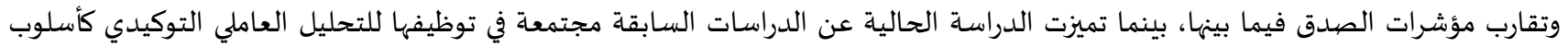

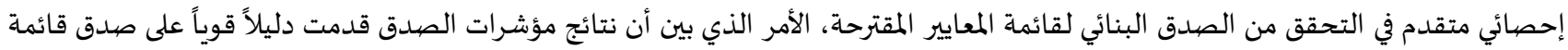

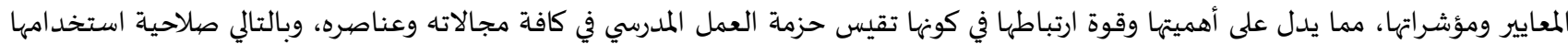

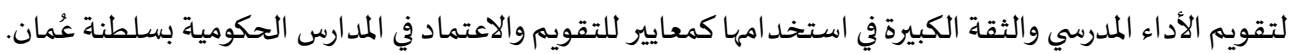

3.4. نتائج السؤال الثالث: والذي ينص على "ما مؤشرات ثبات قائمة معايير التقويم والاعتماد المدرسي للمدارس الحكومية بسلطنة عُمان؟".

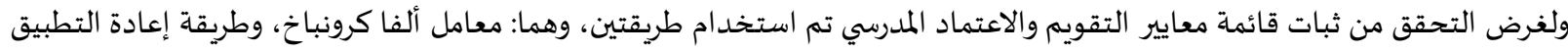

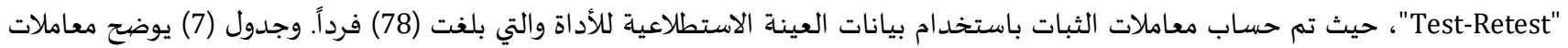
جدول (7): معاملات الثبات لأبعاد الأداة وللأداة ككل

\begin{tabular}{|c|c|c|c|}
\hline إعادة التطبيق (ن*= 36) & ألفا كرونباخ(ن==78) & البعـــــد & s \\
\hline 0.50 & 0.88 & التخطيط الاستراتيجي (الرؤية والرسالة والخطة) & 1 \\
\hline 0.47 & 0.93 & إدارة الموارد (البشرية والممادية) & 2 \\
\hline 0.44 & 0.91 & البيئة المدرسية والمناخ التربوي & 3 \\
\hline 0.59 & 0.85 & المشاركة المجتمعية & 4 \\
\hline 0.62 & 0.87 & المبنى المدرسي وإجراءات الأمن والسلامة & 5 \\
\hline 0.59 & 0.90 & المنهج الدراسي وطرق التدربس المتبعة & 6 \\
\hline 0.67 & 0.81 & أساليب تقويم التحصيل ونتائج الطلبة & 7 \\
\hline 0.40 & 0.92 & مصادر التعلم والمختبرات & 8 \\
\hline 0.55 & 0.92 & الخدمات الطلابية والأنشطة المدرسية & 9 \\
\hline 0.58 & 0.93 & خطة التحسين المدرسية & 10 \\
\hline 0.63 & 0.98 & القيمة الكلية لثبات الأداة & 11 \\
\hline
\end{tabular}

من جدول (7) يتضح أن معاملات الثبات لأبعاد الأداة بطريقة ألفا كرونباخ تراوحت بين (0,81- 0,93)، كما بلغ معامل ثبات الأداة ككل (0,98) وهي معاملات مرتفعة ومقبولة، كما تراوحت معاملات الارتباط للأبعاد بطريقة إعادة التطبيق بين (0,63 )

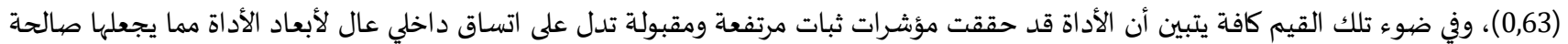

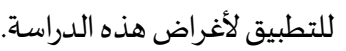


ومقارنة ببعض الدراسـات السابقة التي استخدمت معامل ألفا كرونباخ للتأكد من ثبات الأداة، فإن مؤشرات الثبات لقائمة المعايير في الدراسة

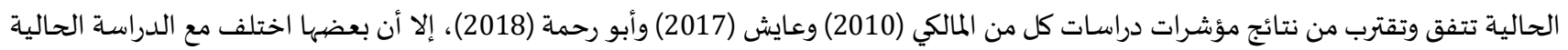

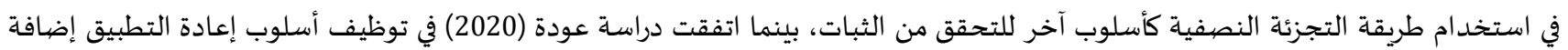
لمعامل ألفا كرونباخ؛ حيث تقاربت قيم معاملات الارتباط بين التطبيقين لكلا الدراستين، الأمر الذي يشير إلى أن قائمة المعايير العشرة التي طرحتهاتها

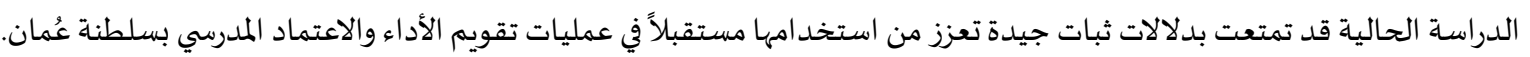
وبشكل عام يتضح أن القائمة المقترحة قد تضمنت بعض المعايير المتفق عليها في بعض الدراسات السابقة؛ حيث اتفقت الدراسة الحالية مع

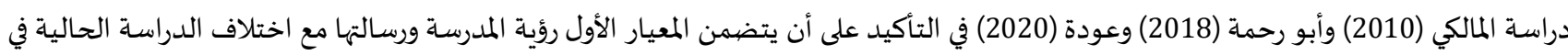

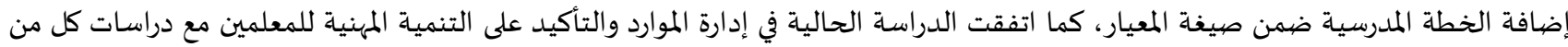

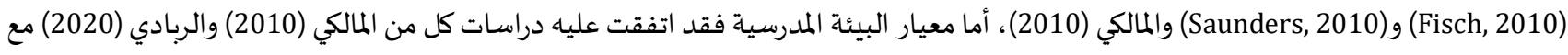

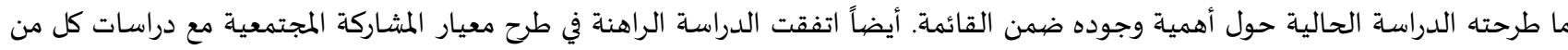
(Fertig, 2007) والنعُمانية (2010) والزاملي وآخرون (2012)، في حين اتفقت مع دراسة السيابي (2012) في معيار المبنى المدرسي وإجراءات الأمن

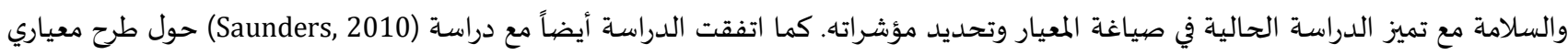

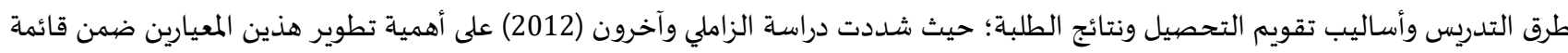

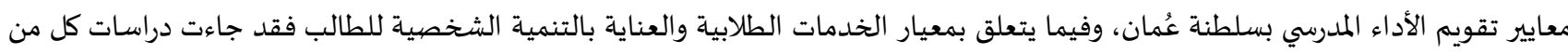

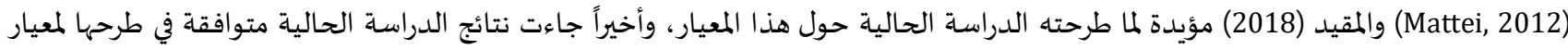
خطة التحسين المدرسية مع دراسة الربادي (2020) على اختلاف صيغة المعيد (لمعيار بين الدراستين. 4.4 التوصيات:

من خلال ما توصلت إليه الدراسة من نتائج يوصي الباحثين بما يلي: يمكن للمختصين في الهيئة العُمانية للاعتماد الأكاديمي وضمان الجودة الاستفادة من هذه المعايير في توظيفها في عمليات التقويم والاعتماد،

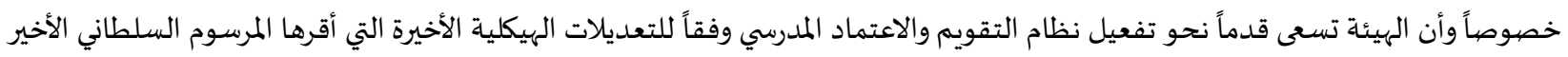
في مهام واختصياصيات الهيئة. العمل على نشر المعايير وآليات توظيفها لكافة شرائح المجتمع المدرسي بمن فيهم الطلبة وأولياء الأمور. عقد دورات تدريبية لفرق التقويمين الذاتي والخارجي ولكافة شرائح العاملين بالمجتمع المدرسي لشرح المعايير وآلية تطبيقها في العمل المدرسي. استخدام المعايير المقترحة في عمليات التقويم الذاتي بالمدارس كخطوة أولى قبل تطبيق نظام الاعتماد.

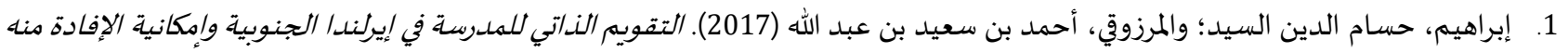

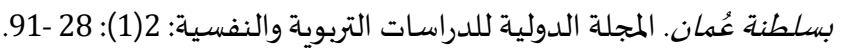

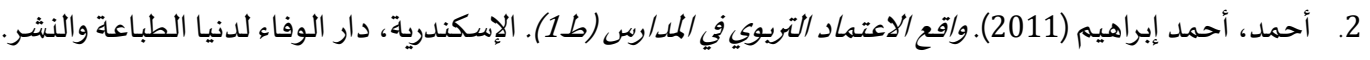

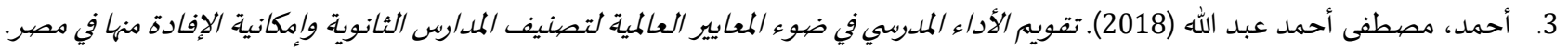

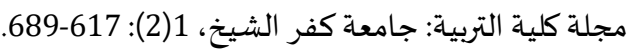

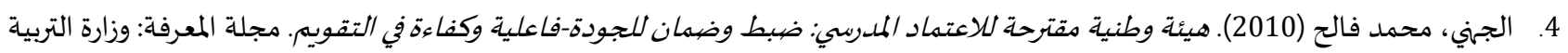
والتعليم، السعودياة. العدد 186.

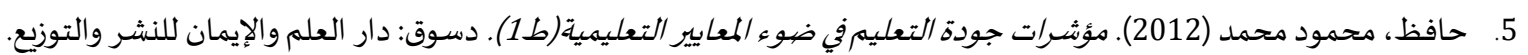
6.

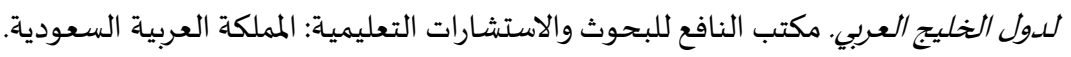
7. الراسبية، أمينة راشد (2020). تقويم الأداء الملدرسي في مدارس الحلقة الثانية من التعليم الأساسي في سلطنة عُمان في ضهوء مدخل إدارة الجودة الشاملة: تصيور مقترح. مجلة العلوم التربوية والدراسات الإنسانية: $4(9)$ (9): 301-333. 8. الربادي، عبد الله علي عبد الله (2020). واقع تطبيق معايير الاعتماد الملدرسي بالمدارس الأهلية بالجمههورية اليمنية. مجلة الآداب للدراسات النفسية والتربوية: 3: 97-158. 


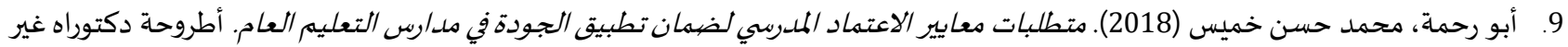
منشورة. كلية الدراسات العليا، جامعة القرآن الكريم وتأصيل العلوم، فلسيطي السين.

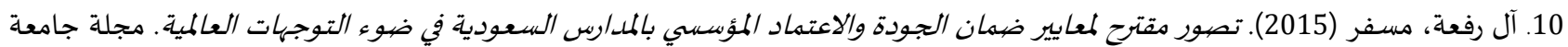

الباحة للعلوم الإنسانية: 2: 119-156.

11. الرميح، ندى صالح (2013). الاعتماد التربوي لبرامج التربية الخاصية. مؤتمر اللقاء السنوي السـادس عشر للجمعية السعودية للعلوم التربوية

والنفسية (جستن)، الاعتماد المدرسي، خلال الفترة 4-6 فبراير، جامعة الملك سعود، الرياض، المملكة العربية السعودية.

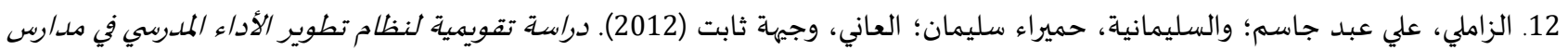

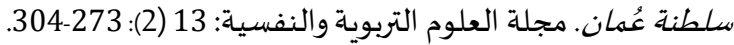
13. الزاملي، علي عبد جاسم؛ والصيارمي، عبد الله محمد؛ وكاظم، علي مهدي (2009). مفاهيم وتطبيقات في التقويم والقياس التويوي (ط أن). الكويت: مكتبة الفلاح للنشر والتوزيع.

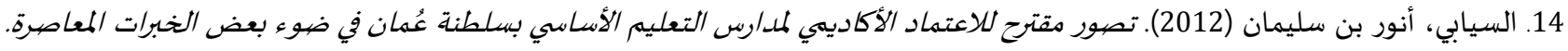

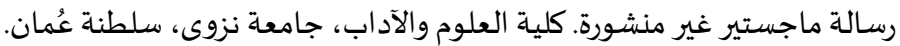
15. عايش، رواء نبيل خليل (2017). معايير الاعتماد والجودة في المدارس الخاصية بمحافظات غزة في ضوء أنموذج سيتا للاعتماد الممدري وسبل

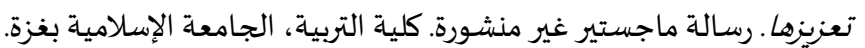

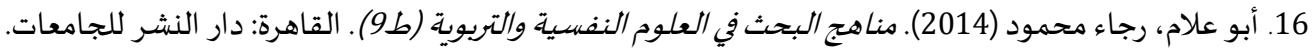

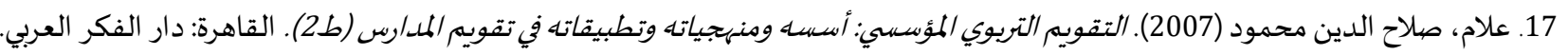
18. عودة، أحمد (2011). معايير ضمان الجودة المشتقة من المتأثرين بنتائج التقييم في الممدرسة: ملدخل متحذبر لتحفيز الاعتماد والجودة. المجلة

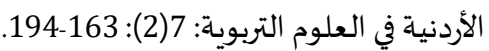

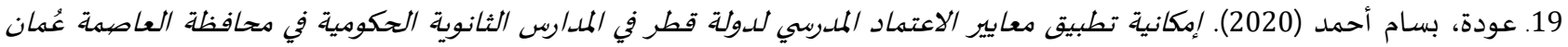
ومعيقات تطبيقها والحلول المقترحة. رسالة ماجستير غير منشورة. كلية العلوم التربوية، جامعة الشرق الأوسط، الأردن. 20. قاسم، مجدي عبد الوهاب؛ ومحمود، حسين بشير؛ وحسن، أحلام الباز (2011). المستويات المعيارية لخربج التعليم قبل الجامعي في الألفية الثالثة. القاهرة: دار الفكر العربي.

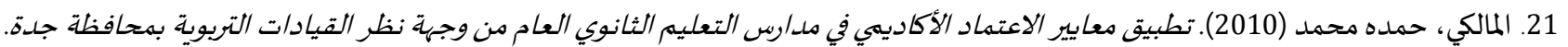
رسالة ماجستير غير منشورة. كلية التربية، جامعة أم القرى، المملكة العبية السعودية. 22. مجاهد، محمد عطوة (2008).ثقافة المعايير والجودة في التعليم. الاسكندرية: دار الجامعة الجديدة الجدئ. 23. مجاهد، محممد عطوة؛ وعناني، هشام فتوح (2011). استراتيجيات الجودة في التعليم. الإسكندرية: دار الجامعة الجديدة.

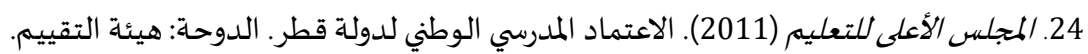

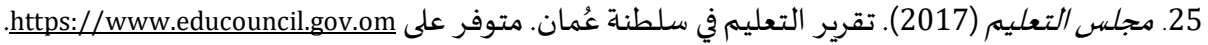

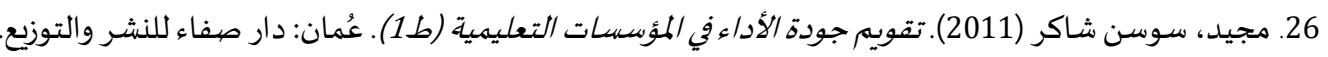

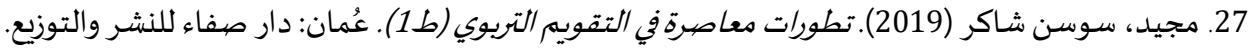
28. مجيد، سوسن شاكر؛ والزيادات، محمد عواد (2008). الجودة في التعليمر - دراسات تطبيقية. عُمان: دار صفئاء للنشر والتوزيع. 29. مخلوف، سميحة علي محمد (2007).تقويم الإدرارة الممدرية في ضوء المعايير القومية للتعليم المصري. مجلة كلية التربية: الزقازيق، 23 (7): 309-

30. المقيد، أسامة محمد اسماعيل (2018). واقع تطبيق معايير نظام الجودة والاعتماد الممرسي في الملدارس الحكومية بمحافظات غزة وعلاقته بمستوى أداء المعلمين. رسالة ماجستير غير منشورة. كلية التربية، الجامعة الإسلامية بغزة.

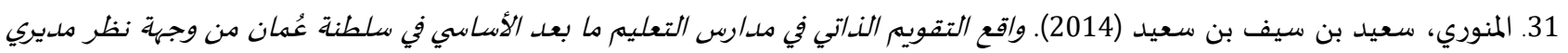

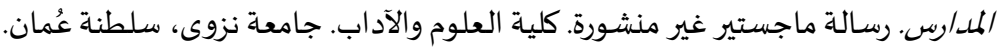

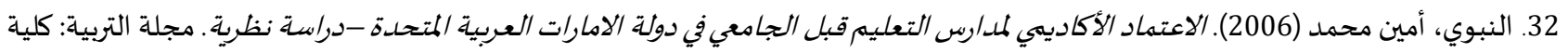
التربية، جامعة الامارات العربية المتحدة، 19: 135-207. 33. النعُمانياة، سلامه بنت سلطان بن حمد (2010). تطوير معايير تقييم الأداء في مدارس سلطناة عُمان. رسالة ماجستير غير منشورة. كلية العلوم والآداب. جامعةة نزوى، سلطنة عُمان. 


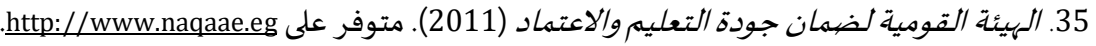

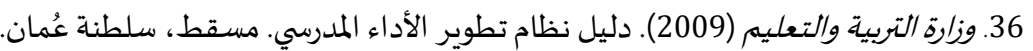

37. وزارة التربية والتعليم (2010). المؤتمر السابع لوزراء التربية والتعليم العرب. مسقط ولم، سلطنة عُمان.

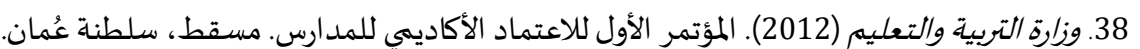

39. وزارة التربية والتعليم (2012). ملخص التقرير حول التعليم في سلطنة عُمان: دراسة مشتركة بين وزارة التربية والتعليم والبنك الدولي. مسقط،

سلطنة عُمان.

40. وزارة الشؤون القانونية (2020). مرسوم سلطاني رقم (2020/79) بشأن تحديد اختصاصات وزارة التربية والتعليم واعتماد هيكلها التنظيمي.

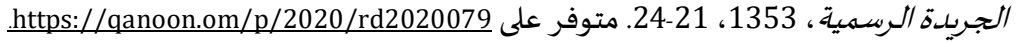

41. وزارة الشؤون القانونية (2021). مرسوم سلطاني رقم (9/ 2021) في شأن الهيئة العُمانية للاعتماد الأكاديمي وضمان جودة التعليم. الجبريدة

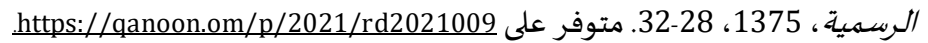

42. اليعربي، سلطان بن سيف بن حمود (2012). فاعلية نظام تطوير الأداء الملدرسي فيفرس ثثافة التقويم الذاتي في مدارس سلطنة عُمان. رسالة

ماجستير غير منشورة. جامعة مؤتة، الأردن.

ثانياً: المراجع الأجنبية:

1. Accreditation Process and Benefits of Accreditation (2012). Available at: http://www.worldwidelearn.com. Visit on 20/12/ 2019.

2. AdvancED Accreditation Standards for Quality Schools (2010). Available at: http://www.advanced.org. Visit on 22/5/2020.

3. Al-Wahaibi, Said S. (2009). Quality Assurance for Accreditation of Private Higher Education Institution in the Sultanate of Oman. Unpublished PHD dissertation. University of Malaya.

4. Bernasconi, A. (2006). Current Trends in the Accreditation of K-12 schools: Cases in the United States, Australia, and Canada. The Journal of Education, 185 (3): 73-82. https://doi.org/10.1177/002205740518500310

5. Burris, R. T. (2008). An Analysis of Accreditation Processes, Quality Control Criteria, Historical Events, and Student Performance. Unpublished PHD dissertation. The University of Central Florida.

6. Fernando, D.; Iraurgi, l. \& Villa, A. (2018). Quality management in schools: Analysis of mediating Factors. South African Journal of Education, 38(2): 1-8. https://doi.org/10.15700/saje.v38n2a1388

7. Fertig, M. (2007). International school accreditation: Between a rock and a hard place. Journal of Research in International Education, 6(3): 333-348. https://doi.org/10.1177/1475240907083199

8. Fisch, B. (2010). Evaluating organizational quality through narrative: a case for accreditation using the school portfolio. International Journal of Leadership in Education, 13(4): 455-487. https://doi.org/10.1080/13603120902814672

9. Fryer, S.D. (2007). Accreditation and Accountability Processes in California High Schools: A Case Study. Unpublished PHD dissertation. Faculty of the Rosier School of Education. The University of Southern California.

10. Hannigan, P.W. (2008). A Study of the Principal ship: Performance Indicators of Leadership Standards and the Work of Principals. Unpublished PHD dissertation. Northern Illinois University.

11. Herman, J. L. (2009). Moving to the Next Generation of Standards for Science: Building on Recent Practices. Los Angles. University of California. Cresst Report NO. 762.

12. Mattei, P. (2012). Raising educational standards: national testing of pupils in the United Kingdom, 1988-2009. Policy Studies, 3(33): 231-247. https://doiorg/10.1080/01442872.2012.658260

13. Middle States Association of Colleges and Schools-MSA (2020). Standards for Accreditation for Schools. http://www.ces-msa.org. Visit on $12 / 11 / 2020$

14. Provezis, S. J. (2010). Regional Accreditation and Learning Outcomes Assessment: Mapping the Territory. Unpublished PHD dissertation. University of Illinois, Urbana.

15. Ross, C. M. (2008). The Role of SACS Accreditation on Student Performance in Virginia's Rural, Town, Suburban, and Urban Public Schools. Unpublished PHD dissertation. Virginia Commonwealth University.

16. Saunders, L. (2010). Information Literacy as a Student Learning Outcome: As Viewed from the Perspective of Institutional Accreditation. Unpublished PHD dissertation, ProQuest, UMI Dissertations Publishing.

17. Woodhead, C. (2002). The Standards of Today and how to raise them to the standards of tomorrow. London, Adam Smith Research. 
المجلة الدولية للدراسـات التربوية والنفسية

International Journal of Educational \& Psychological Studies (EPS)

Journal Homepage: https://www.refaad.com/views/EPSR/Home.aspx

www.refaad.com

ISSN: 2520-4149 (Online) 2520-4130 (Print)

\title{
Construction of school evaluation and accreditation standards for governance schools in the Sultanate of Oman
}

\section{Badriya Hamood Nasser AL-Mahruqi ${ }^{1}$, Ali Abed Jassim Al-Zamili², Mahmoud Mohammad Ibrahim ${ }^{3}$}

${ }^{1}$ Ministry of Education, Sultanate of Oman

2 Associate Professor (former) in the Department of Psychology, College of Education, Sultan Qaboos University, Sultanate of Oman

${ }^{3}$ Associate Professor of Measurement and Evaluation, College of Education, Sultan Qaboos University, Sultanate of Oman

1 Someone4941@gmail.com, ${ }^{2}$ aljassimali3@gmail.com, ${ }^{3}$ Mibrahim@squ.edu.om

\author{
Received : 20/4/2021 Revised : 30/4/2021 Accepted : 8/5/2021 DOI : https://doi.org/10.31559/EPS2021.10.1.11
}

Abstract: The current study aimed at form standards for evaluation and school accreditation for public schools in the Sultanate of Oman, as the study followed the descriptive approach. The sample consisted of (490) administrators and teachers in government schools, administrative supervisors, and supervisors of school performance evaluation in five educational governorates, in addition to supervisors at the Ministry's general office. The study concluded with a list of (10) standards for evaluation and school accreditation, which are: (strategic planning, management of human and financial resources, school environment and educational climate, community participation, the school building, safety and security procedures, the curriculum and teaching methods used, and methods for assessing achievement and student results, learning resources and laboratories, student services and school activities and school improvement plan).In addition, under each criterion, a set of procedural indicators can be inferred through which the level of achievement of the standard can be inferred, which amounted to (78) procedural indicators. The list of standards has high validity and reliability indicators that enhance its use for evaluation and accreditation purposes.

Keywords: School accreditation; Standards; Public schools; Sultanate of Oman.

\section{References:}

1. 'aysh, Rwa' Nbyl Khlyl (2017). M'ayyr Ala'tmad Waljwdh Fy Almdars Alkhash Bmhafzat Ghzh Fy Dw' Anmwdj Syta Lla'tmad Almdrsy Wsbl T'zyzha. Rsalt Majstyr Ghyr Mnshwrh. Klyt Altrbyh, Aljam'h Aleslamyh Bghzh.

2. Abw 'lam, Rja' Mhmwd (2014). Mnahj Albhth Fy Al'lwm Alnfsyh Waltrbwyh (T9). Alqahrh: Dar Alnshr Lljam'at.

3. 'lam, Slah Aldyn Mhmwd (2007). Altqwym Altrbwy Alm'ssy: Assh Wmnhjyath Wttbyqath Fy Tqwym Almdars (T2). Alqahrh: Dar Alfkr Al'rby.

4. 'wdh, Ahmd (2011). M'ayyr Dman Aljwdh Almshtqh Mn Almtathryn Bnta'j Altqyym Fy Almdrsh: Mdkhl Mtjdr Lthfyz Ala'tmad Waljwdh. Almjlh Alardnyh Fy Al'lwm Altrbwyh: 7(2): 163-194.

5. 'wdh, Bsam Ahmd (2020). Emkanyh Ttbyq M'ayyr Ala'tmad Almdrsy Ldwlh Qtr Fy Almdars Althanwyh Alhkwmyh Fy Mhafzt Al'asmh 'uman Wm'yqat Ttbyqha Walhlwl Almqtrhh. Rsalt Majstyr Ghyr Mnshwrh. Klyt Al'lwm Altrbwyh, Jam't Alshrq Alawst, Alardn.

6. Ahmd, Ahmd Ebrahym (2011). Waq' Ala'tmad Altrbwy Fy Almdars (T1). Aleskndryh, Dar Alwfa' Ldnya Altba'h Walnshr.

7. Ahmd, Mstfa Ahmd 'bd Allh (2018). Tqwym Alada' Almdrsy Fy Dw' Alm'ayyr Al'almyh Ltsnyf Almdars Althanwyh Wemkanyh Alefadh Mnha Fy Msr. Mjlt Klyt Altrbyh: Jam't Kfr Alshykh, 1(2): 617-689.

8. Drndry, Eqbal Zyn Al'abdyn؛ Walnaf', 'bd Allh (2009). Bna' Nmwdj Tnzymy Mtkaml Lla'tmad Almdrsy Fy Aldwl Ala'da' Bmktb Altrbyh Al'rby Ldwl Alkhlyj Al'rby. Mktb Alnaf' Llbhwth Walastsharat Alt'lymyh: Almmlkh Al'rbyh Als'wdyh. 
9. Ebrahym, Hsam Aldyn Alsyd; Walmrzwqy, Ahmd Bn S'yd Bn 'bd Allh (2017). Altqwym Aldaty Llmdrsh Fy Eyrlnda Aljnwbyh Wemkanyh Alefadh Mnh Bsltnt 'uman. Almjlh Aldwlyh Lldrasat Altrbwyh Walnfsyh: 2(1): 28 -91.

10. Hafz, Mhmwd Mhmd (2012). M'shrat Jwdt Alt'lym Fy Dw' Alm'ayyr Alt'lymyh(T1). Dswq: Dar Al'lm Waleyman Llnshr Waltwzy'.

11. Aljhny, Mhmd Falh (2010). Hy'eh Wtnyh Mqtrhh Lla'tmad Almdrsy: Dbt Wdman Lljwdh-Fa'lyt Wkfa'h Fy Altqwym. Mjlt Alm'rfh: Wzart Altrbyh Walt'lym, Als'wdyh. Al'dd 186.

12. Almalky, Hmdh Mhmd (2010). Ttbyq M'ayyr Ala'tmad Alakadymy Fy Mdars Alt'lym Althanwy Al'am Mn Wjht Nzr Alqyadat Altrbwyh Bmhafzt Jdh. Rsalt Majstyr Ghyr Mnshwrh. Klyh Altrbyh, Jam't Am Alqra, Almmlkh Al'rbyh Als'wdyh.

13. Mjahd, Mhmd 'twh (2008). Thqaft Alm'ayyr Waljwdh Fy Alt'lym. Alaskndryh: Dar Aljam'h Aljdydh.

14. Mjahd, Mhmd 'twh; W'nany, Hsham Ftwh (2011). Astratyjyat Aljwdh Fy Alt'lym. Aleskndryh: Dar Aljam'h Aljdydh.

15. Almjls Ala'la Llt'lym (2011). Ala'tmad Almdrsy Alwtny Ldwlt Qtr. Aldwhh: Hy't Altqyym.

16. Mjls Alt'lym (2017). Tqryr Alt'lym Fy Sltnt 'uman. Mtwfr 'la https://www.educouncil.gov.om.

17. Mjyd, Swsn Shakr (2011). Tqwym Jwdt Alada' Fy Alm'ssat Alt'lymyh (T1). 'uman: Dar Sfa' Llnshr Waltwzy'.

18. Mjyd, Swsn Shakr (2019). Ttwrat M'asrh Fy Altqwym Altrbwy (T1). 'uman: Dar Sfa' Llnshr Waltwzy'.

19. Mjyd, Swsn Shakr; Walzyadat, Mhmd 'wad (2008). Aljwdh Fy Alt'lym - Drasat Ttbyqyh. 'uman: Dar Sfa' Llnshr Waltwzy'.

20. Mkhlwf, Smyhh 'ly Mhmd (2007). Tqwym Aledarh Almdrsyh Fy Dw' Alm'ayyr Alqwmyh Llt'lym Almsry. Mjlt Klyt Altrbyh: Alzqazyq, 23 (7): 309-364.

21. Almqyd, Asamh Mhmd Asma'yl (2018). Waq' Ttbyq M'ayyr Nzam Aljwdh Wala'tmad Almdrsy Fy Almdars Alhkwmyh Bmhafzat Ghzh W'laqth Bmstwa Ada' Alm'Imyn. Rsalt Majstyr Ghyr Mnshwrh. Klyt Altrbyh, Aljam'h Aleslamyh Bghzh.

22. Qasm, Mjdy 'bd Alwhab; Wmhmwd, Hsyn Bshyr; Whsn, Ahlam Albaz (2011). Almstwyat Alm'yaryh Lkhryj Alt'lym Qbl Aljam'y Fy Alalfyh Althalthh. Alqahrh: Dar Alfkr Al'rby.

23. Alrasbyh, Amynh Rashd (2020). Tqwym Alada' Almdrsy Fy Mdars Alhlqh Althanyh Mn Alt'lym Alasasy Fy Sltnt 'uman Fy Dw' Mdkhl Edart Aljwdh Alshamlh: Tswr Mqtrh. Mjlt Al'lwm Altrbwyh Waldrasat Alensanyh: 4(9): 301-333.

24. Alrbady, 'bd Allh 'ly 'bd Allh (2020). Waq' Ttbyq M'ayyr Ala'tmad Almdrsy Balmdars Alahlyh Baljmhwryh Alymnyh. Mjlt Aladab Lldrasat Alnfsyh Waltrbwyh: 3: 97-158.

25. Al Rf'h, Msfr (2015). Tswr Mqtrh Lm'ayyr Dman Aljwdh Wala'tmad Alm'ssy Balmdars Als'wdyh Fy Dw' Altwjhat Al'almyh. Mjlt Jam't Albahh Ll'lwm Alensanyh: 2: 119-156.

26. Abw Rhmh, Mhmd Hsn Khmys (2018). Mttlbat M'ayyr Ala'tmad Almdrsy Ldman Ttbyq Aljwdt Fy Mdars Alt'lym Al'am. Atrwht Dktwrah Ghyr Mnshwrh. Klyt Aldrasat Al'lya, Jam't Alqran Alkrym Wtasyl Al'lwm, Flstyn.

27. Alrmeh, Nda Salh (2013). Ala'tmad Altrbwy Lbramj Altrbyh Alkhash. M'tmr Allqa' Alsnwy Alsads 'shr Lljm'yh Als'ewdyh Ll'lwm Altrbwyh Walnfsyh (Jstn), Ala'tmad Almdrsy, Khlal Alftrh 4-6 Fbrayr, Jam't Almlk S'ewd, Alryad, Almmlkh Al'rbyh Als'wdyh

28. Alzamly, 'ly 'bd Jasm; Walslymanyh, Hmyra' Slyman; Al'any, Wjyhh Thabt (2012). Drash Tqwymyh Lnzam Ttwyr Alada' Almdrsy Fy Mdars Sltnt 'uman. Mjlt Al'lwm Altrbwyh Walnfsyh: 13 (2): 273-304.

29. Alzamly, 'ly 'bd Jasm; Walsarmy, 'bd Allh Mhmd; Wkazm, 'ly Mhdy (2009). Mfahym Wttbyqat Fy Altqwym Walqyas Altrbwy (T1). Alkwyt: Mktbh Alflah Llnshr Waltwzy'.

30. Alsyaby, Anwr Bn Slyman (2012). Tswr Mqtrh Lla'tmad Alakadymy Lmdars Alt'lym Alasasy Bsltnt 'uman Fy Dw' B'd Alkhbrat Alm'asrh. Rsalt Majstyr Ghyr Mnshwrh. Klyt Al'lwm Waladab, Jam't Nzwa, Sltnt 'uman. 